ES/ER/TM-95/R4

\title{
Toxicological Benchmarks for Screening Contaminants of Potential Concern for Effects on Sediment-Associated Biota: 1997 Revision
}


ES/ER/TM-95/R4

\title{
Toxicological Benchmarks for Screening Contaminants of Potential Concern for Effects on Sediment-Associated Biota: 1997 Revision
}

\author{
D. S. Jones, LMER \\ G. W. Suter II, LMER \\ R. N. Hull, Beak Consultants, Ltd.
}

Date Issued—November 1997

\author{
Prepared for the \\ U.S. Department of Energy \\ Office of Environmental Management \\ under budget and reporting code EW 20 \\ LOCKHEED MARTIN ENERGY SYSTEMS, INC. \\ managing the \\ Environmental Management Activities at the \\ East Tennessee Technology Park \\ Oak Ridge Y-12 Plant Oak Ridge National Laboratory \\ Paducah Gaseous Diffusion Plant Portsmouth Gaseous Diffusion Plant \\ under contract DE-AC05-84OR21400 \\ for the \\ U.S. DEPARTMENT OF ENERGY
}




\section{AUTHOR AFFILIATIONS}

D. S. Jones and G. W. Suter II are members of the Environmental Sciences Division of Oak Ridge National Laboratory, Lockheed Martin Energy Research Corporation. R. N. Hull is currently affiliated with Beak Consultants, Ltd., Brampton, Ontario. 


\section{PREFACE}

The purpose of this report, Toxicological Benchmarks for Screening Contaminants of Potential Concern for Effects on Sediment-Associated Biota: 1997 Revision (ES/ER/TM-95/R4), is to present sediment benchmark data and discuss their use as benchmarks for determining the level of toxicological effects on sediment-associated biota and to briefly describe three categories of approaches to the development of sediment quality benchmarks. This work was performed under Work Breakdown Structure 1.4.12.2.3.04.05.04 (Activity Data Sheet 8304, “Technical Integration—Risk Assessment”). Publication of this document meets a milestone for the Environmental Restoration Risk Assessment Program. This report is an update of two prior reports (Jones et al. 1997; Jones et al. 1996; and Hull and Suter 1994). It contains new benchmarks for freshwater sediments, equilibrium partitioning benchmarks corrected to two significant figures, and all of the freshwater and estuarine benchmarks included in the previous version. 


\section{CONTENTS}

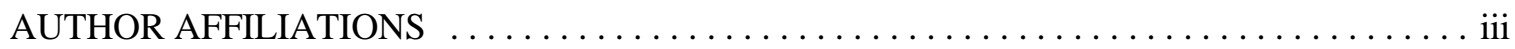

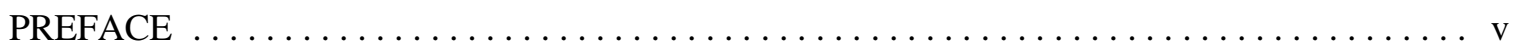

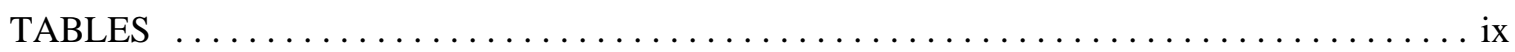

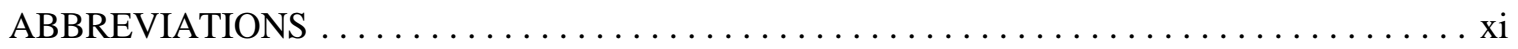

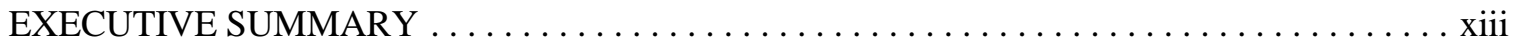

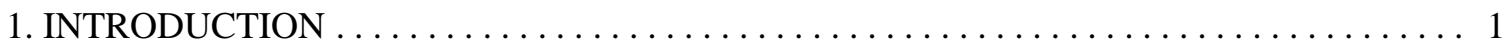

2. REVIEW OF POSSIBLE APPROACHES TO BENCHMARK DEVELOPMENT $\ldots \ldots \ldots 2$

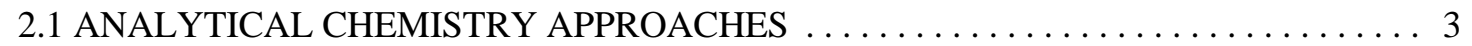

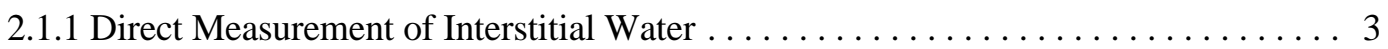

2.1.2 Estimation of Interstitial Water Concentrations: Sediment/Water EqP Approach . . . 3

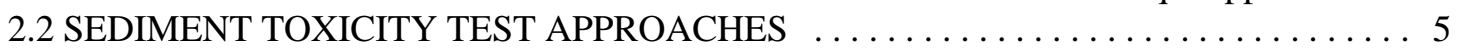

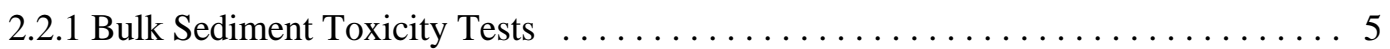

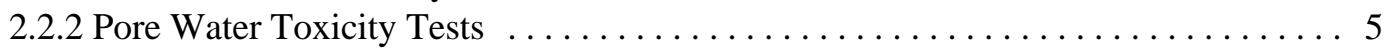

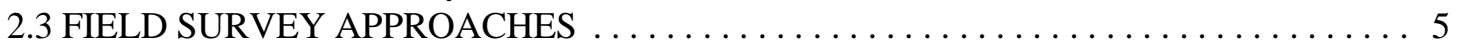

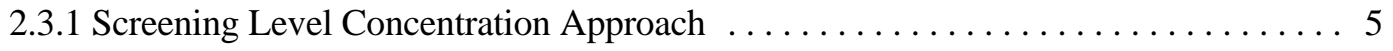

2.3.2 Apparent Effects Threshold Approach $\ldots \ldots \ldots \ldots \ldots \ldots \ldots \ldots \ldots \ldots \ldots 6$

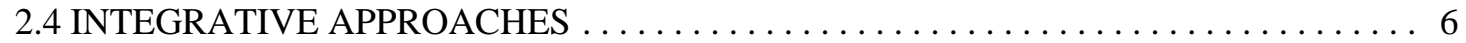

2.4.1 National Oceanic and Atmospheric Administration Approach . . . . . . . . . 6

2.4.2 Florida Department of Environmental Protection Approach . . . . . . . . . . . . 7

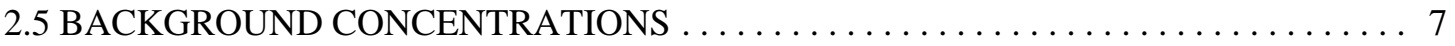

3. RECOMMENDED SEDIMENT BENCHMARKS $\ldots \ldots \ldots \ldots \ldots \ldots \ldots \ldots \ldots \ldots \ldots \ldots$

3.1 MARINE AND ESTUARINE SEDIMENTS $\ldots \ldots \ldots \ldots \ldots \ldots \ldots \ldots \ldots \ldots$

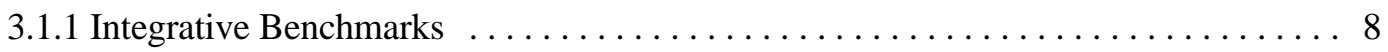

3.1.2 Apparent Effects Thresholds $\ldots \ldots \ldots \ldots \ldots \ldots \ldots \ldots \ldots \ldots \ldots \ldots \ldots$

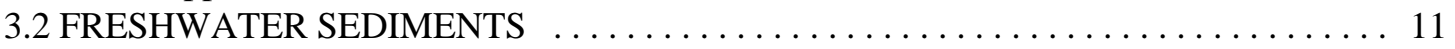

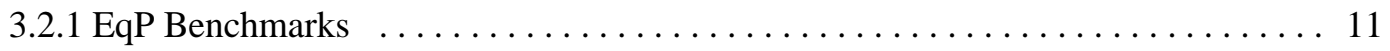

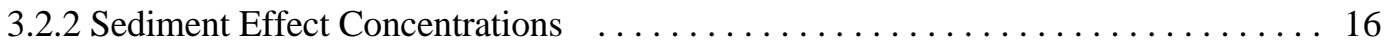

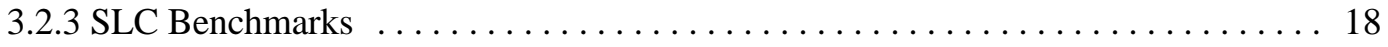

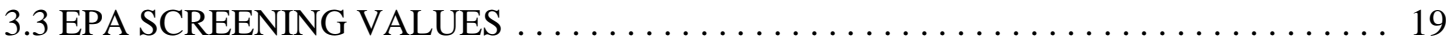

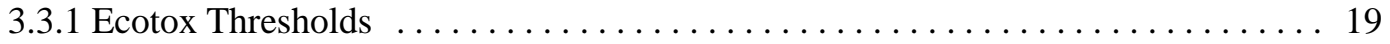

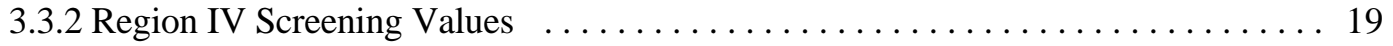

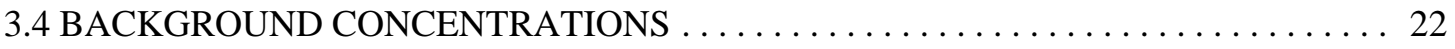

4. BENCHMARK USE IN BASELINE ECOLOGICAL RISK

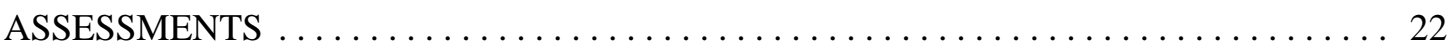




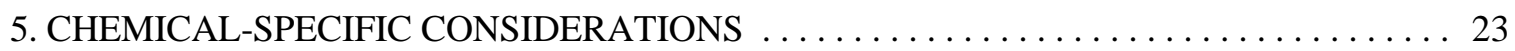

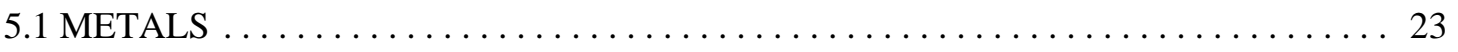

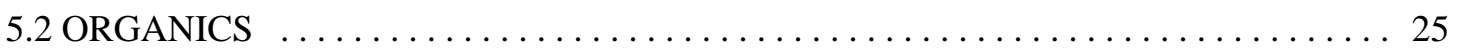

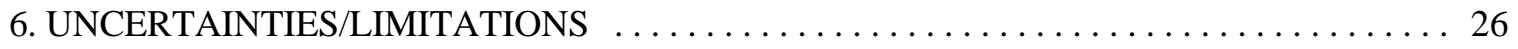

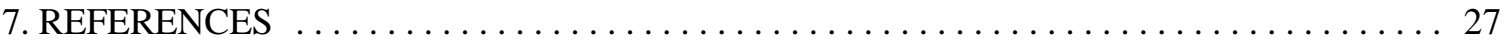

APPENDIX. SUMMARY OF ALL SEDIMENT EFFECT CONCENTRATIONS THAT MEET THE MINIMUM REQUIREMENTS FOR RECOMMENDATION .... A-1 


\section{TABLES}

1 Summary of selected integrative sediment quality benchmarks for marine and estuarine

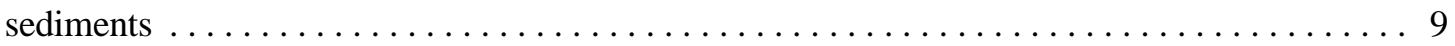

2 Washington state sediment quality standards for ionizable organic compounds $\ldots \ldots \ldots \ldots 11$

3 Summary of EqP-derived sediment quality benchmarks for nonionic organic chemicals corresponding to conventional aqueous benchmarks $\ldots \ldots \ldots \ldots \ldots 12$

4 Summary of selected toxicity test- and screening level concentration-based

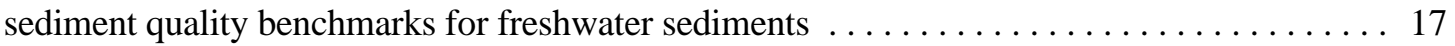

5 EPA Region IV and OSWER sediment screening values $\ldots \ldots \ldots \ldots \ldots \ldots \ldots \ldots \ldots \ldots$ 


\section{ABBREVIATIONS}

\begin{tabular}{|c|c|}
\hline AET & apparent effects threshold \\
\hline ARCS & Assessment and Remediation of Contaminated Sediment \\
\hline ASTM & American Society for Testing and Materials \\
\hline AVS & acid volatile sulfide \\
\hline CERCLA & Comprehensive Environmental Response, Compensation, and Liability Act \\
\hline DOC & dissolved organic carbon \\
\hline DOE & U.S. Department of Energy \\
\hline EPA & U.S. Environmental Protection Agency \\
\hline $\mathrm{EqP}$ & equilibrium partitioning \\
\hline ERA & ecological risk assessment \\
\hline ER-L & Effects Range-Low \\
\hline ER-M & Effects Range-Median \\
\hline ET & Ecotox Threshold \\
\hline FDEP & Florida Department of Environmental Protection \\
\hline $\mathrm{f}_{\mathrm{oc}}$ & fraction organic carbon \\
\hline $\mathrm{K}_{\mathrm{oc}}$ & organic carbon/water partition coefficient \\
\hline $\mathrm{K}_{\mathrm{ow}}$ & octanol/water partition coefficient \\
\hline $\mathrm{K}_{\mathrm{p}}$ & sediment/water partition coefficient \\
\hline NAWQC & National Ambient Water Quality Criteria \\
\hline NEC & high No Effect Concentration \\
\hline NOAA & National Oceanic and Atmospheric Administration \\
\hline $\mathrm{OC}$ & organic carbon \\
\hline OECD & Organization for Economic Cooperation and Development \\
\hline Ontario MOE & Ontario Ministry of the Environment \\
\hline ORNL & Oak Ridge National Laboratory \\
\hline ORR & Oak Ridge Reservation \\
\hline OSWER & Office of Solid Waste and Emergency Response \\
\hline PAHs & polycyclic aromatic hydrocarbons \\
\hline $\mathrm{PCBs}$ & polychlorinated biphenyls \\
\hline PEC & probable effect concentration \\
\hline PEL & Probable Effects Level \\
\hline PQL & Practical Quantitation Limit \\
\hline SEC & sediment effect concentration \\
\hline SEM & simultaneously extracted metal \\
\hline SLC & screening level concentration \\
\hline SQB & sediment quality benchmark \\
\hline SQC & sediment quality criteria \\
\hline SSLC & species screening level concentration \\
\hline TEC & threshold effect concentration \\
\hline TEL & Threshold Effects Level \\
\hline TIE & toxicity identification evaluation \\
\hline TOC & total organic carbon \\
\hline WQB & water quality benchmark \\
\hline WQC & water quality criteria \\
\hline
\end{tabular}




\section{EXECUTIVE SUMMARY}

A hazardous waste site may contain hundreds of chemicals; therefore, it is important to screen contaminants of potential concern for the ecological risk assessment. Often this screening is done as part of a screening assessment, the purpose of which is to evaluate the available data, identify data gaps, and screen contaminants of potential concern. Screening may be accomplished by using a set of toxicological benchmarks. These benchmarks are helpful in determining whether contaminants warrant further assessment or are at a level that requires no further attention. If a chemical concentration or the reported detection limit exceeds a proposed lower benchmark, further analysis is needed to determine the hazards posed by that chemical. If, however, the chemical concentration falls below the lower benchmark value, the chemical may be eliminated from further study.

The use of multiple benchmarks is recommended for screening chemicals of concern in sediments. Integrative benchmarks developed for the National Oceanic and Atmospheric Administration and the Florida Department of Environmental Protection are included for inorganic and organic chemicals. Equilibrium partitioning benchmarks are included for screening nonionic organic chemicals. Freshwater sediment effect concentrations developed as part of the U.S. Environmental Protection Agency's (EPA's) Assessment and Remediation of Contaminated Sediment Project are included for inorganic and organic chemicals (EPA 1996). Field survey benchmarks developed for the Ontario Ministry of the Environment are included for inorganic and organic chemicals. In addition, EPA-proposed sediment quality criteria are included along with screening values from EPA Region IV and Ecotox Threshold values from the EPA Office of Solid Waste and Emergency Response. Pore water analysis is recommended for ionic organic compounds; comparisons are then made against water quality benchmarks.

This report is an update of three prior reports (Jones et al. 1997; Jones et al. 1996; and Hull and Suter 1994). It contains new benchmarks for freshwater sediments, equilibrium partitioning benchmarks corrected to two significant figures, and all of the freshwater and estuarine benchmarks included in the previous version. 


\section{INTRODUCTION}

A hazardous waste site may contain hundreds of chemicals; therefore, it is important to screen contaminants of potential concern for the ecological risk assessment (ERA). Often this screening is done as part of a screening assessment, the purpose of which is to evaluate the available data, identify data gaps, and screen contaminants of potential concern (Suter 1995). Screening may be accomplished by using a set of toxicological benchmarks. These benchmarks are helpful in determining whether contaminants warrant further assessment or are at a level that requires no further attention. If a chemical concentration or the reported detection limit exceeds a lower benchmark, further analysis is needed to determine the hazards posed by that chemical. If, however, the chemical concentration falls below the lower benchmark value, the chemical may be eliminated from further study. Concentrations exceeding an upper screening benchmark indicate that the chemical in question is clearly of concern and that remedial actions are likely to be needed.

The use of multiple benchmarks also indicates the likelihood and nature of effects. For example, exceedance of only one conservatively estimated benchmark may provide weak evidence of real effects, whereas exceedance of multiple benchmarks of varying conservatism may provide strong evidence of real effects. Likewise, if a nonionic organic chemical only exceeds benchmarks that are not normalized to site-specific organic carbon content, then organisms that ingest sediment may be more exposed than those that do not. These inferences can be used to refine future sampling and remediation efforts.

In recent years, protecting sediment quality has been viewed as a logical and necessary extension of water quality protection (Adams et al. 1992). The U.S. Environmental Protection Agency (EPA) is authorized to develop and implement sediment quality criteria (SQC) under Section 304(a) of the Clean Water Act (EPA 1989a). EPA released five SQC documents in 1993 (EPA 1993a-e). In addition, EPA Region IV (1995) and the Office of Solid Waste and Emergency Response (OSWER) (1996) released sediment screening values in 1995. Until EPA's task is complete, efforts will continue around the United States and abroad (EPA 1996; MacDonald 1993; Persaud et al. 1993) to develop SQC and benchmark values for the assessment of sediment quality at hazardous waste sites.

Sediment quality benchmarks (SQBs) are necessary, in addition to water quality benchmarks (WQBs), because (1) various toxic contaminants found in only trace amounts in the water column accumulate in sediments to elevated levels; (2) sediments serve as both a reservoir and a source of contaminants to the water column; (3) sediments integrate contaminant concentrations over time, whereas water column contaminant concentrations are much more variable and dynamic; (4) sediment contaminants in addition to water column contaminants affect benthic and other sediment-associated organisms; and (5) sediments are an integral part of the aquatic environment, providing habitat, feeding, and rearing areas for many aquatic organisms (Chapman 1989).

To make decisions as to whether a chemical or biological measurement of sediment quality indicates impairment, site-specific data may be compared with benchmarks that indicate whether sediment quality is acceptable. Existing criteria and standards are considered a type of benchmark. The purpose of this report is to present sediment benchmark data and discuss their use as benchmarks for determining the level of toxicological effects on sediment-associated biota. 
It is important to note that these benchmarks do not represent remediation goals. Remediation goals must consider adverse effects on habitat and remobilization of contaminants caused by removal or remediation of sediments.

The benchmarks in this report are to be used at the U.S. Department of Energy's (DOE's) Oak Ridge Reservation (ORR) and at the Portsmouth and Paducah gaseous diffusion plants as screening values only to show the nature and extent of contamination and identify the need for additional site-specific investigation (e.g., biological and chemical testing).

Sediment benchmarks also can be used for baseline ERAs, which are required under the Comprehensive Environmental Response, Compensation, and Liability Act (CERCLA) at Superfund sites. These assessments evaluate the risks to the environment posed by the hazardous waste site. Sediment benchmarks must not be used as the sole measure of sediment toxicity. Field studies and toxicity tests will be the primary indicators of toxicity of sediments; benchmarks may be used to determine which chemicals present in the sediment are most likely causing the toxicity. This integrative approach allows a more accurate evaluation of adverse ecological impact, which is necessary in a baseline risk assessment.

This report is an update of three prior reports (Jones et al. 1997; Jones et al. 1996; and Hull and Suter 1994). It contains new benchmarks for freshwater sediments, equilibrium partitioning benchmarks corrected to two significant figures, and all of the freshwater and estuarine benchmarks included in the previous version.

\section{REVIEW OF POSSIBLE APPROACHES TO BENCHMARK DEVELOPMENT}

Three distinct categories of approaches can be used in the development of SQBs. These approaches are based on analytical chemistry, toxicity test results, and field survey data. A fourth integrative approach incorporates all three types of data. Regardless of the method, a numeric benchmark results.

The scientific and regulatory communities are still debating the best methods to be used to develop sediment quality guidelines. This diversity of opinion is demonstrated by the wide variety of methods being studied and by the fact that the state of Washington has implemented sediment quality standards based on the apparent effects threshold (AET) approach, whereas the equilibrium partitioning (EqP) approach is favored by the EPA Office of Water (EPA 1996). Additionally, the Organization for Economic Cooperation and Development (OECD) recommended three methods for deriving sediment quality objectives: the EqP approach, the measurement of interstitial water, and spiked sediment toxicity tests (OECD 1992). Several of the possible approaches to developing SQBs have been reviewed (Adams et al. 1992; MacDonald et al. 1992; MacDonald 1994; Chapman 1989) and are briefly described in the following sections. 


\subsection{ANALYTICAL CHEMISTRY APPROACHES}

\subsubsection{Direct Measurement of Interstitial Water}

The direct measurement of interstitial water approach compares the concentrations of contaminants in sediment interstitial (pore) waters with the EPA water quality criteria (WQC) (EPA 1993f) and other WQBs. WQBs of varying conservatism have been developed at Oak Ridge National Laboratory (ORNL) (Suter and Tsao 1996) because many chemicals do not have national ambient WQC. Maughan (1993) suggests that the analysis of sediment pore water is a more appropriate method for screening than using bulk sediment chemistry. He cites the advantages of the flexibility and acceptance of pore water testing.

It can be argued that benthic organisms are exposed to contaminants via other exposure routes, such as dermal absorption and ingestion of sediment particles. An analysis of the feeding habits of freshwater benthic species concluded that these species were not sediment ingesters, except for the oligochaetes (aquatic earthworms) and some chironomids that are both filter feeders and occasional sediment ingesters (Adams 1987). In contrast to this, marine burrowing species frequently ingest sediment (Adams 1987). For the clam Macoma nasuta, uptake of highly lipophilic pollutants occurred primarily by ingestion of solids (63-84\%), followed by ventilation of interstitial water across the gills (11-12\%) (Boese et al. 1990). This may be because Macoma nasuta predominantly ventilates overlying water, not interstitial water.

Such discrimination between overlying and interstitial water also may be important for tube dwellers (e.g., chironomids, hexagenia) that pump overlying water through their burrows (Landrum and Robbins 1990). Maughan (1993) argues that if the organism is in equilibrium with the pore water, then the concentration in the pore water would reflect the sum of all exposure routes. Therefore, an organism that has accumulated contaminants, through feeding, at a higher concentration than the equilibrium with pore water would reestablish the equilibrium by losing contaminants to the pore water (Maughan 1993). However, factors may influence whether the organism can establish an equilibrium with the pore water. For example, diffusion within the interstitial water may limit transfer of desorbed compounds to the organism (Landrum and Robbins 1990).

\subsubsection{Estimation of Interstitial Water Concentrations: Sediment/Water EqP Approach}

\subsubsection{Nonionic organics}

This approach calculates a bulk sediment chemical concentration benchmark. The calculation uses the WQBs together with correction factors for the effects of organic carbon (OC) (EPA 1993f). By using this method, a SQB is calculated as follows (EPA 1993f): If the WQB (micrograms per liter) is a water quality benchmark for the chemical of interest (Suter and Tsao 1996), then the SQB (micrograms per kilogram sediment) is computed by using the partition coefficient $\mathrm{K}_{\mathrm{p}}$ (liters per kilogram sediment) between sediment and water:

$$
\mathrm{SQB}=\mathrm{K}_{\mathrm{p}} \times \mathrm{WQB}
$$

The partitioning of nonionic chemicals between particles and water depends on the partition coefficient $\mathrm{K}_{\mathrm{oc}}$ for the particles' OC and the mass fraction of OC ( $\mathrm{f}$ oc kilograms OC per kilogram sediment) of the particles:

$$
\mathrm{K}_{\mathrm{p}}=\mathrm{f}_{\mathrm{oc}} \times \mathrm{K}_{\mathrm{oc}} .
$$


Where the $\mathrm{K}_{\mathrm{oc}}$ is unavailable, it is estimated by the octanol-water partition coefficient $\mathrm{K}_{\mathrm{ow}}$ of the chemical for sediments by using the following equation (Di Toro 1985):

$$
\log _{10}\left(\mathrm{~K}_{\mathrm{oc}}\right)=0.00028+0.983 \log _{10}\left(\mathrm{~K}_{\mathrm{ow}}\right) \text {. }
$$

Therefore,

$$
\mathrm{SQB}=\mathrm{f}_{\mathrm{oc}} \times \mathrm{K}_{\mathrm{oc}} \times \mathrm{WQB}
$$

The EqP approach requires four major assumptions: (1) partitioning of the organic chemical between OC and interstitial water is stable at equilibrium; (2) the sensitivities of benthic species and species tested to derive WQBs, predominantly water column species, are similar; (3) the levels of protection afforded by WQBs are appropriate for benthic organisms; and (4) exposures are similar regardless of feeding type or habitat (EPA 1993a).

EqP can be used only if $\mathrm{f}_{o c}>0.2 \%$. At $\mathrm{f}_{\mathrm{oc}}<0.2 \%$, the factors controlling second-order effects on partitioning (e.g., particle size, sorption to nonorganic mineral fractions) become relatively more important (EPA 1993f).

For both the direct measurement and EqP approaches for estimating pore water effects concentrations, it is assumed that the WQBs, when applied to the interstitial water of sediments, would protect infaunal organisms. EPA (1993f) has concluded that the sensitivities of benthic species are sufficiently similar to those of water column species to tentatively permit the use of WQBs for the derivation of SQBs.

The EqP approach is favored by the EPA over the direct measuring of pore water approach (EPA 1993f). The free chemical concentration in pore water can be estimated directly from the OC normalized sediment concentration, and the estimate is independent of the dissolved organic carbon (DOC) concentration. Using the pore water chemical concentration to estimate the free pore water chemical concentration requires that the DOC concentration and the DOC partition coefficient be known; this is because the proportion of a chemical in pore water that is complexed to DOC can be substantial. However, it is the free, uncomplexed component that is bioavailable and that is in equilibrium with the OC normalized sediment concentration. Therefore, for highly hydrophobic chemicals and where there is significant DOC complexing, the solid-phase chemical concentration gives a more direct estimate of the bioavailable pore water contaminant concentration than do the pore water concentrations (EPA 1993f).

\subsubsection{Metals}

EqP approach. Significant complexities are associated with inorganic chemicals when using the EqP approach. Uptake (and therefore effects) of sediment-associated contaminants is largely a function of bioavailability. Bioavailability is strongly influenced by a complex suite of physical, chemical, and biological factors in the sediments. Trace metals can be adsorbed at particle surfaces, bound to carbonates, occluded in iron and/or manganese oxyhydroxides, bound to organic matter, bound to sulphide, bound to a matrix, or dissolved in the interstitial water. The complexity of trace metal bioavailability associated with these phases hinders the prediction of effects (Campbell and Tessier 1991).

Acid volatile sulfide method. Acid volatile sulfide (AVS) is a reactive pool of solid-phase sulfide that is available to bind metals and render that portion unavailable and nontoxic to biota (Di Toro et al. 
1992). The AVS is extracted from sediment using hydrochloric acid. The metal concentration that is simultaneously extracted is termed the simultaneously extracted metal (SEM). For [SEM]/[AVS] $<1$, no acute toxicity (mortality $>50 \%$ ) has been observed in any sediment for any benthic test organism. For $[\mathrm{SEM}] /[\mathrm{AVS}]>1$, less sensitive organisms can tolerate increased metal activity. However, the mortality of sensitive species (e.g., amphipods) increases in the range of 1.5 to $2.5 \mu \mathrm{mol}$ of SEM/ $\mu \mathrm{mol}$ of AVS (Di Toro et al. 1992). For this reason, the AVS method is used only to predict when a sediment in not acutely toxic.

The AVS approach requires the measurement of all toxic SEMs that are present in amounts that would contribute significantly to the SEM sum. Failure to do so could lead to an incorrect conclusion of lack of acute toxicity (Di Toro et al. 1992). Use of the AVS method would be invalid if the sediment AVS content is very low. This would occur in fully oxidized sediments (Adams et al. 1992). In addition, only five metals $(\mathrm{Cd}, \mathrm{Cu}, \mathrm{Pb}, \mathrm{Ni}$, and $\mathrm{Zn}$ ) currently can be evaluated using AVS (EPA 1994), and the AVS method has not been adapted for chronic toxicity.

\subsection{SEDIMENT TOXICITY TEST APPROACHES}

\subsubsection{Bulk Sediment Toxicity Tests}

Organisms are exposed to either contaminated field-collected sediments or background sediments spiked in the laboratory with known amounts of single chemicals or mixtures. Mortality or sublethal effects are observed, and dose-response relationships are determined (Chapman 1989; Long and Morgan 1991). A major advantage to this approach is that it follows the methods used to develop WQC; therefore, the procedure and rationale are technically acceptable and legally defensible (Chapman 1989). The use of sediment toxicity tests has become firmly entrenched in many dredged material permitting and benthic survey programs (Burton and Scott 1992).

\subsubsection{Pore Water Toxicity Tests}

Sediment pore water can be used in standardized toxicity tests, and toxicity identification evaluation (TIE) procedures can be used to characterize, identify, and then confirm the toxic components of a complex aqueous solution. However, TIE procedures may be difficult and costly (Maughan 1993). Currently, no universally accepted method for extracting pore water from sediment exists. In addition, pore water is difficult to extract from sediment without potentially altering the toxicity of the pore water (Maughan 1993).

\subsection{FIELD SURVEY APPROACHES}

\subsubsection{Screening Level Concentration Approach}

The screening level concentration (SLC) approach estimates the highest concentration of a particular contaminant in sediment that can be tolerated by approximately $95 \%$ of benthic infauna (Neff et al. 1988). The SLC is derived from synoptic data on sediment chemical concentrations and benthic invertebrate distributions. First, the species screening level concentration (SSLC) is calculated by plotting the frequency distribution of the contaminant concentrations over all sites (at least 10) where the species is present. The 90th percentile of this distribution is taken as the SSLC for that species. Next, a large number of SSLCs are plotted as a frequency distribution to determine the contaminant 
concentration above which 95\% of the SSLCs occur. This final concentration is the SLC (Neff et al. 1988).

The SLC approach has several advantages: it can be used with any chemical contaminant, it can be developed using existing databases and methodologies, and it does not require a priori assumptions concerning mechanisms of interaction between organisms and toxic contaminants (Chapman 1989). Disadvantages include the following: a large amount of field data is required, a precise level of infaunal taxonomic identification is required, calculation of SLCs is affected by the range and distribution of contaminant concentrations and species, selection criteria for species have not been established, and no mechanism has been established to separate single contaminant effects from the effects of all contaminants combined (Chapman 1989).

\subsubsection{Apparent Effects Threshold Approach}

The AET approach uses data from matched sediment chemistry and biological effects measures. Biological effects could be assessed by either benthic community survey or sediment toxicity tests. An AET concentration is the sediment concentration of a selected chemical above which statistically significant biological effects always occur (EPA 1989b). This concentration is alternatively identified as the high No Effect Concentration (NEC) (EPA 1996).

The major strengths of the approach are that (1) combined chemical effects can be considered (EPA 1989b); (2) there are no constraints on the type of contaminant or biological effects that can be used; (3) contaminants that are most likely associated with observed biological effects are identified on a site-specific basis; and (4) because observed biological effects always occur above the AET, the approach provides values based on noncontradictory evidence of biological impacts (Chapman 1989). Disadvantages to this approach include the following: (1) it is site-specific (EPA 1989b), (2) it may be underprotective because biological effects are observed at chemical concentrations well below AET values, (3) it requires a large database for chemical variables and at least one biological indicator, and (4) combined contaminant effects cannot be separated from single contaminant effects (Chapman 1989).

\subsection{INTEGRATIVE APPROACHES}

\subsubsection{National Oceanic and Atmospheric Administration Approach}

Because the EqP approach is impractical for inorganics, other benchmark values were needed. The National Oceanic and Atmospheric Administration (NOAA) annually collects and chemically analyzes sediment samples from sites located in coastal marine and estuarine environments throughout the United States. These data were used to evaluate three basic approaches to the establishment of effects-based criteria: the EqP approach, the spiked-sediment toxicity test approach, and various methods of evaluating synoptically collected biological and chemical data in field surveys (Long and Morgan 1991). Chemical concentrations observed or predicted by these methods to be associated with biological effects were ranked, and the lower 10th percentile [Effects Range-Low (ER-L)] and median [Effects Range-Median (ER-M)] concentrations were identified.

The ER-L and ER-M values were recalculated by Long et al. (1995) after omitting a small amount of freshwater data included in the Long and Morgan (1991) calculations and adding more recent data. 


\subsubsection{Florida Department of Environmental Protection Approach}

The Florida Department of Environmental Protection (FDEP) approach (MacDonald 1994) is similar to the NOAA approach. The updated and revised data set used by Long et al. (1995) also was used by MacDonald (1994) to calculate Threshold Effects Levels (TELs) and Probable Effects Levels (PELs); these data are presented by MacDonald et al. (1994). However, unlike the ER-Ls and ER-Ms, the TELs and PELs also incorporate chemical concentrations observed or predicted to be associated with no adverse biological effects (no effects data). Specifically, the TEL is the geometric mean of the 15th percentile in the effects data set and the 50th percentile in the no effects data set. The PEL is the geometric mean of the 50th percentile in the effects data set and the 85th percentile in the no effects data set. Therefore, the TEL represents the upper limit of the range of sediment contaminant concentrations dominated by no effects data. The PEL represents the lower limit of the range of contaminant concentrations that are usually or always associated with adverse biological effects (MacDonald 1994).

\subsection{BACKGROUND CONCENTRATIONS}

Comparison of site contaminant levels with background levels is a simple screening method. The assumption is that concentrations that are not higher than background are not hazardous. Appropriate background samples must be obtained for waste site samples. The American Society for Testing and Materials (ASTM) is currently developing guidelines for selection of sediment and soil background sampling locations (ASTM Sect. E47.13.01, Task E).

This approach has two major disadvantages: it has no biological effects basis, and it cannot be used for synthetic organic compounds, which should not be present in background sediments. Therefore, it is not appropriate to use this approach as the only screening method. However, it is appropriate to use the background concentrations to screen the other sediment benchmarks, such that sediment benchmarks that are within the range of background concentrations are not used to identify chemicals of potential ecological concern.

\section{RECOMMENDED SEDIMENT BENCHMARKS}

The following section presents the recommended sediment benchmarks for use at DOE's ORR and at the Portsmouth and Paducah gaseous diffusion plants. The rationale, interpretation, and general considerations for using these benchmarks in screening sediment chemical data are also briefly discussed. Chemical-specific considerations are presented in Chap. 4.

This revision includes a new set of toxicity test-based benchmarks for freshwater sediments (EPA 1996) and previously presented benchmarks for marine and estuarine sediments (e.g., FDEP TELs and PELs, NOAA ER-Ls and ER-Ms, Washington state AET, EPA screening values). The freshwater benchmarks are recommended for use at the aforementioned DOE sites. The marine benchmarks are retained and recommended for use because the parties to the Federal Facility Agreement have not yet sanctioned the use of the freshwater benchmarks and because freshwater benchmarks are not available for all chemicals. The use of multiple benchmarks of varying conservatism is recommended to provide

a robust evaluation of the chemical data. That is, a suite of benchmarks reduces the chances of missing a chemical of potential ecological concern and increases the interpretive value of the chemical data set. 
It is strongly recommended that the suite of benchmarks, or the rules for selecting a subset of benchmarks, be explicitly included in the Data Quality Objectives process to get early and informed regulator agreement for their use in a given project.

\subsection{MARINE AND ESTUARINE SEDIMENTS}

\subsubsection{Integrative Benchmarks}

EPA Region IV (1995) has recommended the NOAA and FDEP values as potential lower screening values, and EPA OSWER (1996) has recommended the NOAA values as potential ecotoxicological threshold values. The NOAA and FDEP values also are supported by ORNL as SQBs when bulk sediment chemical concentrations are available.

The data compiled by MacDonald et al. (1994) are from marine and estuarine locations only. The use of the NOAA and FDEP values for freshwater is appropriate in the absence of reliable freshwater sediment benchmarks. Klapow and Lewis (1979) investigated the question of whether or not it was legitimate to combine freshwater and marine aqueous toxicity data to develop marine water quality benchmarks. A statistical test of medians was applied to freshwater and marine acute toxicity data for nine metals (As, $\mathrm{Cd}, \mathrm{Cr}, \mathrm{Cu}, \mathrm{Pb}, \mathrm{Hg}, \mathrm{Ni}, \mathrm{Ag}$, and $\mathrm{Zn}$ ) and nonchlorinated phenolic compounds. In only one case $(\mathrm{Cd})$ was there a statistically significant difference in the median response of marine and freshwater organisms. The NOAA and FDEP values were developed from data from several investigations throughout the United States, and these studies used different approaches to evaluate sediment quality (e.g., toxicity tests, EqP, AET). It is assumed that the use of numerous data and the calculation of percentiles help eliminate the influence of a single (possibly outlier) data point, thereby making the sediment quality values more credible (Long and Morgan 1991).

The NOAA values may be used to help identify sites with the potential to cause adverse biological effects. These are not NOAA criteria or standards and are not intended for use in regulatory decisions or any other similar applications (Long and Morgan 1991). The available NOAA and FDEP values are presented in Table 1.

\subsubsection{Apparent Effects Thresholds}

The AET is the sediment chemical concentration above which statistically significant biological effects always occur (EPA 1989b). Therefore, they may be underprotective because biological effects are observed at chemical concentrations well below AET values (Chapman 1989). AET values for several ionic and polar organic chemicals are retained in this revision because of the significant complexities associated with using the EqP approach.

Organic compounds that are polar or ionic include methyl and thiocarbamates, triazines, amines and analines, and organic acid pesticides (aliphatic and aromatic acids and esters, phenoxy compounds, and ureas). Unlike nonpolar and nonionic organic contaminants, both polar and ionic organic compounds may adsorb onto sediments by a variety of mechanisms, including hydrophobic interaction, nonspecific ion association, ion exchange, ion-dipole interactions, hydrogen bonding, and complex formation by surface metals (Shea 1988). It is possible that a multiple-term model might account for polar organic partitioning between sediment and aqueous phases but such a model does not exist (Shea 1988). 
Table 1. Summary of selected integrative sediment quality benchmarks for marine and estuarine sediments ${ }^{a}$

\begin{tabular}{|c|c|c|c|c|}
\hline \multirow[b]{2}{*}{ Chemical } & \multicolumn{2}{|c|}{$\mathbf{N O A A}^{b}$} & \multicolumn{2}{|c|}{ FDEP $^{c}$} \\
\hline & ER-L & ER-M & TEL & PEL \\
\hline Antimony & $2^{d}$ & $25^{d}$ & & \\
\hline Arsenic & 8.2 & 70 & 7.24 & 41.6 \\
\hline Cadmium & 1.2 & 9.6 & 0.68 & 4.21 \\
\hline Chromium & 81 & 370 & 52.3 & 160 \\
\hline Copper & 34 & 270 & 18.7 & 108 \\
\hline Lead & 46.7 & 218 & 30.2 & 112 \\
\hline Mercury & 0.15 & 0.71 & 0.13 & 0.7 \\
\hline Nickel & 20.9 & 51.6 & 15.9 & 42.8 \\
\hline Silver & 1.0 & 3.7 & 0.73 & 1.77 \\
\hline Zinc & 150 & 410 & 124 & 271 \\
\hline \multicolumn{5}{|c|}{ Organics $(\mu g / k g$ dry weight) } \\
\hline Acenaphthene & 16 & 500 & 6.71 & 88.9 \\
\hline Acenaphthylene & 44 & 640 & 5.87 & 128 \\
\hline Anthracene & 85.3 & 1100 & 46.9 & 245 \\
\hline Benz(a)anthracene & 261 & 1600 & 74.8 & 693 \\
\hline Benzo(a)pyrene & 430 & 1600 & 88.8 & 763 \\
\hline \multicolumn{5}{|l|}{$\mathrm{BHC}$} \\
\hline \multicolumn{5}{|l|}{ BHC, alpha- } \\
\hline \multicolumn{5}{|l|}{ BHC, beta- } \\
\hline Bis(2-ethylhexyl)phthalate & & & 182 & 2647 \\
\hline Chlordane & $0.5^{d}$ & $6^{d}$ & 2.26 & 4.79 \\
\hline Chrysene & 384 & 2800 & 108 & 846 \\
\hline DDD, o,p'- + p,p'- & $2^{d}$ & $20^{d}$ & & \\
\hline DDD, p,p'- & & & 1.22 & 7.81 \\
\hline DDE, p,p'- & 2.2 & 27 & 2.07 & 374 \\
\hline DDT, o,p'- + p,p'- & $1^{d}$ & $7^{d}$ & & \\
\hline DDT, p,p'- & & & 1.19 & 4.77 \\
\hline DDT, Total $^{e}$ & 1.58 & 46.1 & 3.89 & 51.7 \\
\hline Dibenzo(a,h)anthracene & 63.4 & 260 & 6.22 & 135 \\
\hline Dieldrin & $0.02^{d}$ & $8^{d}$ & 0.72 & 4.3 \\
\hline Endrin & $0.02^{d}$ & $45^{d}$ & & \\
\hline Fluoranthene & 600 & 5100 & 113 & 1494 \\
\hline Fluorene & 19 & 540 & 21.2 & 144 \\
\hline Lindane (gamma-BHC) & & & 0.32 & 0.99 \\
\hline 2-Methyl naphthalene & 70 & 670 & 20.2 & 201 \\
\hline Naphthalene & 160 & 2100 & 34.6 & 391 \\
\hline
\end{tabular}


10

Table 1 (continued)

\begin{tabular}{|c|c|c|c|c|}
\hline \multirow[b]{2}{*}{ Chemical } & \multicolumn{2}{|c|}{ NOAA $^{b}$} & \multicolumn{2}{|c|}{ FDEP $^{c}$} \\
\hline & ER-L & ER-M & TEL & PEL \\
\hline PAH, Total LMW ${ }^{f}$ & 552 & 3160 & 312 & 1442 \\
\hline PAH, Total HMW HM $^{f}$ & 1700 & 9600 & 655 & 6676 \\
\hline PAH, Totalf & 4022 & 44792 & 1684 & 16770 \\
\hline PCB, Total & 22.7 & 180 & 21.6 & 189 \\
\hline Phenanthrene & 240 & 1500 & 86.7 & 544 \\
\hline Pyrene & 665 & 2600 & 153 & 1398 \\
\hline
\end{tabular}

${ }^{a}$ Benchmark values are presented herein with the same number of significant digits used in the source document.

${ }^{b} \mathrm{NOAA}=$ National Oceanic and Atmospheric Administration; ER-L = Effects Range-Low;

ER-M = Effects Range-Median; except where noted, effects levels are the updated and revised values from Long et al. (1995).

${ }^{c}$ FDEP $=$ Florida Department of Environmental Protection; TEL $=$ threshold effects level; PEL = probable effects level; source document is MacDonald (1994).

${ }^{d}$ Source document is Long and Morgan (1991).

${ }^{e}$ Total DDT is the sum of the concentrations of the o,p'- and p,p'- isomers of DDD, DDE, and DDT.

${ }^{f} \mathrm{LMW}=$ low molecular weight and is the sum of the concentrations of acenaphthene, acenaphthylene, anthracene, fluorene, 2-methylnaphthalene, naphthalene, and phenanthrene; HMW = high molecular weight and is the sum of the concentrations of benz(a)anthracene, benzo(a)pyrene, chrysene, dibenzo(a,h)anthracene, fluoranthene, and pyrene; Total is the sum of the concentrations of the aforementioned low and high molecular weight PAHs.

The behavior of ionic organic pollutants has not been extensively studied. As with the nonionic organic chemicals, OC appears to be a critical factor in the partitioning behavior in sediments (Jafvert 1990). The critical micelle concentration (Di Toro et al. 1990) and pH (Jafvert 1990) also appear to be dominating factors.

The state of Washington has developed sediment quality standards for some polar and ionic organic compounds (Table 2). AET are site-specific and should be used cautiously. Because little information is available for ionic organics, these contaminants should not be eliminated in a screening risk assessment. Preliminary comparisons can be made to the Washington state sediment quality standards to give an indication of the magnitude of the contamination. In addition, EqP SQBs for two of the polar chemicals (2-methylphenol and phenol) are presented in Table 3.

WQBs do exist for several of these chemicals (Suter and Tsao 1996). If pore water concentrations of these chemicals are available, they should be screened against those benchmarks; this was the methodology followed in the Phase I Screening ERA for the Clinch River (Cook et al. 1992). 
Table 2. Washington state sediment quality standards for ionizable organic compounds (micrograms per kilogram dry weight)

\begin{tabular}{lc}
\hline \multicolumn{1}{c}{ Compound } & $\begin{array}{c}\text { Washington state sediment } \\
\text { quality standard }\end{array}$ \\
\hline Benzoic acid & 650 \\
Benzyl alcohol & 57 \\
Pentachlorophenol & 360 \\
Phenol & 420 \\
2-Methyl phenol & 63 \\
4-Methyl phenol & 670 \\
2,4-Dimethyl phenol & 29 \\
\hline
\end{tabular}

Source: Ginn and Pastorak 1992

\subsection{FRESHWATER SEDIMENTS}

\subsubsection{EqP Benchmarks}

The EPA has chosen the EqP approach for developing SQC for nonionic organics (EPA 1993f). This is also a methodology that ORNL supports for developing SQBs when bulk sediment concentrations and WQBs are available.

The EqP approach requires a WQB, a $\mathrm{K}_{\mathrm{oc}}$ value, and a measured or assumed site-specific total organic carbon (TOC) value. Because many chemicals do not have National Ambient Water Quality Criteria (NAWQC), sets of WQBs of varying conservatism have been developed at ORNL (Suter and Tsao 1996); consult this publication, or its most recent revision, for a complete discussion of the aquatic benchmarks and their uses. Secondary chronic values are intended to be conservative predictors of effects. If concentrations exceed benchmarks that used the NAWQC, the chemicals must be contaminants of concern because the NAWQC are applicable or relevant and appropriate requirements. Concentrations that exceed Lowest Chronic Value benchmarks indicate a risk of real effects. Table 3 lists available $\log \mathrm{K}_{\mathrm{ow}}$ values for selected nonionic organic contaminants, sources of these values, calculated $\log \mathrm{K}_{\mathrm{oc}}$ values, and estimated SQBs corresponding to the conventional aqueous benchmarks; these SQBs are normalized assuming $1 \%$ TOC.

For polar organic chemicals, adsorption mechanisms other than hydrophobicity may significantly increase the fraction of the chemical sorbed to the sediment particles (EPA 1993f). Therefore, the $\mathrm{K}_{\mathrm{oc}}$-based model is likely to overestimate the free, and therefore bioavailable, chemical concentration. SQBs for selected polar nonionic organic chemicals are included in Table 3 as conservative benchmarks and are denoted appropriately.

The bulk sediment contaminant concentrations measured at a site can be compared directly to the SQBs presented in Table 3. It is recommended, however, that these benchmarks be adjusted by multiplying the SBQ by the site-specific percent TOC. For example, the SQC for acenaphthene is 1300 $\mu \mathrm{g} / \mathrm{kg}$ assuming $1 \%$ TOC and 13,000 $\mu \mathrm{g} / \mathrm{kg}$ assuming 10\% TOC (EPA 1993a). However, the 
Table 3. Summary of EqP-derived sediment quality benchmarks for nonionic organic chemicals corresponding to conventional aqueous benchmarks

\begin{tabular}{|c|c|c|c|c|c|c|c|}
\hline \multirow[b]{2}{*}{ Chemical } & \multirow[b]{2}{*}{$\log \operatorname{Kow}^{b}$} & \multirow[b]{2}{*}{ Log Koc } & \multirow[b]{2}{*}{ NAWQC chronic } & \multirow[b]{2}{*}{$\begin{array}{l}\text { Secondary } \\
\text { chronic value }\end{array}$} & \multicolumn{3}{|c|}{ Lowest chronic value } \\
\hline & & & & & Fish & Daphnids & $\begin{array}{c}\text { Nondaphnid } \\
\text { invertebrates }\end{array}$ \\
\hline Acenaphthene & 3.92 & 3.85 & $1300^{c}$ & & 5300 & 470,000 & 16,000 \\
\hline Acetone $^{d}$ & -0.24 & -0.24 & & 8.7 & 3000 & 9.1 & \\
\hline Anthracene & 4.55 & 4.47 & & 220 & 27 & $<620$ & \\
\hline Benzene & 2.13 & 2.09 & & 160 & & $>120,000$ & \\
\hline Benzidine $^{d}$ & 1.66 & 1.63 & & 1.7 & 57 & & \\
\hline Benzo(a)anthracene & 5.70 & 5.60 & & 110 & & 2600 & \\
\hline Benzo(a)pyrene & 6.11 & 6.01 & & 140 & & 3000 & \\
\hline Benzyl alcohol ${ }^{d}$ & 1.11 & 1.09 & & 1.1 & 73 & & \\
\hline BHC (lindane) & 3.73 & 3.67 & 3.7 & & 680 & 670 & 150 \\
\hline BHC (other) & $3.80^{e}$ & 3.74 & & 120 & & 5200 & \\
\hline Biphenyl & $3.96^{f}$ & 3.89 & & 1100 & & & \\
\hline Bis(2-ethylhexyl)phthalate & $7.60^{g}$ & 7.47 & & 890,000 & & & \\
\hline 4-Bromophenyl phenyl ether & 5.00 & 4.92 & & 1200 & & & \\
\hline Butylbenzyl phthalate & 4.84 & 4.76 & & 11,000 & & & \\
\hline 2-Butanone ${ }^{d}$ & $0.29^{g}$ & 0.29 & & 270 & 5400 & 27,000 & \\
\hline Carbon disulfide & 2.00 & 1.97 & & 0.85 & 8800 & 230 & \\
\hline Carbon tetrachloride & 2.73 & 2.68 & & 47 & 9500 & 27,000 & \\
\hline Chlordane & 6.32 & 6.21 & 2800 & & 26,000 & 260,000 & 18,000 \\
\hline Chlorobenzene & 2.86 & 2.81 & & 410 & 7800 & 97,000 & \\
\hline Chloroform & 1.92 & 1.89 & & 22 & 960 & 3500 & \\
\hline p,p'-DDD & 6.10 & 6.00 & & 110 & 17,000 & & \\
\hline
\end{tabular}


Table 3 (continued)

\begin{tabular}{|c|c|c|c|c|c|c|c|}
\hline \multirow[b]{2}{*}{ Chemical } & \multirow[b]{2}{*}{$\log \operatorname{Kow}^{b}$} & \multirow[b]{2}{*}{ Log Koc } & \multirow[b]{2}{*}{ NAWQC chronic } & \multirow[b]{2}{*}{$\begin{array}{c}\text { Secondary } \\
\text { chronic value }\end{array}$} & \multicolumn{3}{|c|}{ Lowest chronic value } \\
\hline & & & & & Fish & Daphnids & $\begin{array}{c}\text { Nondaphnid } \\
\text { invertebrates }\end{array}$ \\
\hline DDT & 6.53 & 6.42 & & $340^{\text {bf }}$ & 19,000 & 420 & \\
\hline Decane & $5.01^{g}$ & 4.93 & & 41,000 & & $6,600,000$ & \\
\hline Diazinon & $3.70^{f}$ & 3.64 & & 1.9 & & & \\
\hline Dibenzofuran & $4.12^{g}$ & 4.05 & & 420 & & 110,000 & \\
\hline 1,2-Dichlorobenzene & 3.43 & 3.37 & & 330 & & & \\
\hline 1,3-Dichlorobenzene & $3.43^{f}$ & 3.37 & & 1700 & & & \\
\hline 1,1-Dichloroethene & 2.13 & 2.09 & & 31 & $>3500$ & 5900 & \\
\hline 1,2-Dichloroethene & $1.86^{e}$ & 1.83 & & 400 & 6400 & & \\
\hline 1,3-Dichloropropene & 2.00 & 1.97 & & 0.051 & 220 & 740 & \\
\hline Dieldrin & 5.37 & 5.28 & $110^{c}$ & & & & \\
\hline Diethyl phthalate & 2.50 & 2.46 & & 600 & & & \\
\hline Endosulfan, all isomers & 4.10 & 4.03 & & 5.5 & & & \\
\hline Endrin & 5.06 & 4.97 & $42^{c}$ & & & & \\
\hline Ethyl benzene & 3.14 & 3.09 & & 89 & $>5400$ & 160,000 & \\
\hline
\end{tabular}


Table 3 (continued)

\begin{tabular}{|c|c|c|c|c|c|c|c|}
\hline \multirow[b]{2}{*}{ Chemical } & \multirow[b]{2}{*}{$\log \mathbf{K o w}^{b}$} & \multirow[b]{2}{*}{ Log Koc } & \multirow[b]{2}{*}{ NAWQC chronic } & \multirow[b]{2}{*}{$\begin{array}{c}\text { Secondary } \\
\text { chronic value }\end{array}$} & \multicolumn{3}{|c|}{ Lowest chronic value } \\
\hline & & & & & Fish & Daphnids & $\begin{array}{c}\text { Nondaphnid } \\
\text { invertebrates }\end{array}$ \\
\hline Hexane & $3.90^{8}$ & 3.83 & & 40 & $4,500,000$ & & \\
\hline 2-Hexanone ${ }^{d}$ & $1.38^{8}$ & 1.36 & & 22 & 7400 & & \\
\hline Methoxychlor & 5.08 & 4.99 & & 19 & & & \\
\hline 1-Methylnaphthalene & $3.87^{8}$ & 3.80 & & 130 & 34,000 & & \\
\hline 4-Methyl-2-pentanone ${ }^{d}$ & $1.31^{g}$ & 1.29 & & 33 & 15,000 & & \\
\hline 2-Methylphenol ${ }^{d}$ & 1.99 & 1.96 & & 12 & 440 & 1200 & \\
\hline Methylene chloride & 1.25 & 1.23 & & 370 & 18,000 & 7200 & \\
\hline Naphthalene & 3.36 & 3.30 & & 240 & 12,000 & 23,000 & \\
\hline 2-Octanone ${ }^{d}$ & $2.37^{8}$ & 2.33 & & 18 & & & \\
\hline $\begin{array}{l}\text { PCBs } \\
\text { Aroclor® } 1221\end{array}$ & $4.70^{h}$ & 4.62 & & 120 & 25,000 & & \\
\hline Aroclor ${ }^{\circledR} 1232$ & $5.10^{h}$ & 5.01 & & 600 & 130,000 & & \\
\hline Aroclor@ 1242 & $5.60^{h}$ & 5.51 & & 170 & 29,000 & & 16,000 \\
\hline Aroclor ${ }^{\circledR} 1248$ & $6.20^{h}$ & 6.09 & & 1000 & & & \\
\hline Aroclor® 1254 & $6.50^{h}$ & 6.39 & & 810 & & 71,000 & \\
\hline Aroclor® 1260 & $6.80^{h}$ & 6.68 & & $4,500,000$ & $<63,000$ & & \\
\hline Pentachlorobenzene & 5.26 & 5.17 & & 700 & & & \\
\hline 1-Pentanol ${ }^{d}$ & $1.51^{8}$ & 1.48 & & 34 & 9300 & & \\
\hline Phenanthrene & 4.55 & 4.47 & $1800^{c}$ & & & 59,000 & \\
\hline Phenol & 1.48 & 1.46 & 31 & & $<57$ & 570 & \\
\hline 2-Propanol ${ }^{d}$ & 0.05 & 0.05 & & 0.084 & 6.6 & & \\
\hline 1,1,2,2 Tetrachloroethane & 2.39 & 2.35 & & 1400 & 5400 & 22,000 & \\
\hline
\end{tabular}




\section{Table 3 (continued)}

\begin{tabular}{|c|c|c|c|c|c|c|c|}
\hline \multirow[b]{2}{*}{ Chemical } & \multirow[b]{2}{*}{$\log \operatorname{Kow}^{b}$} & \multirow[b]{2}{*}{ Log Koc } & \multirow[b]{2}{*}{ NAWQC chronic } & \multirow[b]{2}{*}{$\begin{array}{c}\text { Secondary } \\
\text { chronic value }\end{array}$} & \multicolumn{3}{|c|}{ Lowest chronic value } \\
\hline & & & & & Fish & Daphnids & $\begin{array}{l}\text { Nondaphnid } \\
\text { invertebrates }\end{array}$ \\
\hline Tetrachloroethene & 2.67 & 2.62 & & 410 & 3500 & 3200 & \\
\hline Toluene & 2.75 & 2.70 & & 50 & 6400 & 130,000 & \\
\hline 1,2,4-Trichlorobenzene & 4.01 & 3.94 & & 9600 & & & \\
\hline 1,1,1-Trichloroethane & 2.48 & 2.44 & & 30 & 9600 & & \\
\hline 1,1,2-Trichloroethane & 2.05 & 2.02 & & 1200 & 9700 & 19,000 & \\
\hline Trichloroethene & 2.71 & 2.66 & & 220 & 51,000 & 33,000 & \\
\hline
\end{tabular}

${ }^{a}$ Conventional aqueous benchmarks are presented in Suter and Tsao (1996). EqP = equilibrium partioning. All sediment benchmarks are in $\mu \mathrm{g} / \mathrm{kg}$ and are estimated to two significant figures assuming $1 \%$ TOC. Estimated sediment quality benchmarks greater than $10 \%(100,000,000 \mu \mathrm{g} / \mathrm{kg})$ are not included because such concentrations are assumed to be exceedingly unlikely under natural conditions [applies to bis(2-ethylhexyl)phthalate and di-n-octylphthalate].

${ }^{b}$ Log Kow values are from EPA (1995a), except where noted otherwise.

Denotes proposed EPA sediment quality criteria.

${ }^{d}$ Denotes polar nonionic organic compounds, for which the EqP model is likely to provide a conservative estimate of exposure.

${ }^{e}$ Most conservative (i.e., lowest) recommended value for reported configurations. BHC (other) is lowest of alpha-, beta-, and delta-BHC, only.

SSource is EPA (1995b).

${ }^{8}$ Source is search of Syracuse Research Corporation, Environmental Sciences Center's on-line Experimental Log P Database conducted on June 7, 1996.

${ }^{h}$ Source is ATSDR (1989). 
EqP methodology, and therefore these benchmarks, is not appropriate for sediments with less than $0.2 \%$ TOC (EPA 1993f).

\subsubsection{Sediment Effect Concentrations}

The National Biological Service produced a set of sediment benchmarks for the EPA Great Lakes National Program Office as part of the Assessment and Remediation of Contaminated Sediment (ARCS) Project (EPA 1996). Sediment effect concentrations (SECs) were calculated using laboratory data on the toxicity of contaminants associated with up to 62 sediment samples collected predominantly from freshwater sites. The exception was six samples from Mobile Bay, Alabama, and five samples from Galveston Bay, Texas, which were used, with $10 \%$ salinity in the overlying water, in one of the three tests. The test organisms and the measured endpoints were (1) reduction in survival, growth, or sexual maturation of the amphipod Hyalella azteca and (2) reduction in survival or growth of the midge Chironomus riparius. SECs were calculated for 14-day C. riparius tests, 14-day H. azteca tests, and 28-day H. azteca tests. Three of the methods previously discussed were used to calculate SECs for each of these tests: the NOAA method for ER-Ls and ER-Ms, the FDEP method for TELs and PELs, and the AET method for NECs. Therefore, up to 15 SECs were calculated for each contaminant (e.g., 5 SECs for each of 3 tests). Each SEC was evaluated for its ability to correctly classify samples in the database as toxic or nontoxic (EPA 1996). Table A.1 in the Appendix presents the key results of this process, including the percentage of nontoxic samples incorrectly classified as toxic (\% False Positive), the percentage of toxic samples incorrectly classified as nontoxic (\% False Negative), and the overall percentage of samples correctly classified as toxic or nontoxic (\% Total Correct). We selected a subset of the SECs for each chemical on the basis of these results.

ER-Ls and ER-Ms are generally as reliable as paired TELs and PELs (EPA 1996). Therefore, one of the three ERLs and three TELs for each chemical was selected as the representative threshold effect concentration (TEC). Similarly, a representative probable effect concentration (PEC) was selected for each chemical from the three ERMs and three PELs. A representative high No Effect Concentration also was selected for each chemical from the three NECs. The NECs are generally higher than the other benchmarks and tend to decrease the percentage of false positives, but increase the percentage of false negatives, relative to the other SECs (EPA 1996). Table 4 presents the representative benchmarks, which were selected by screening each SEC against a set of minimum requirements and then ranking the SECs relative to each other based on their reliability and conservatism.

The first requirement for all representative benchmarks is that the \% Total Correct had to be greater than $50 \%$. This is an intuitively obvious minimum criterion, which can be thought of as requiring a benchmark to improve the odds of correct sample classification over that of a toss of a fair coin. A second criterion is necessary because the first requirement ignores the fact that two SECs can have the same \% Total Correct value, but different \% False Positive and \% False Negative values. For TECs, the second minimum requirement is that the $\%$ False Negatives must be less than $25 \%$. For PECs and NECs, the second minimum requirement is that the $\%$ False Positives must be less than $25 \%$. The differences in the second minimum requirements reflect the differences in the intended use and interpretation of these benchmarks. TECs are intended to be relatively conservative screening values, below which effects are rarely expected to occur. As such, it is important to limit the likelihood of incorrectly excluding a site and chemical from further consideration. PECs and NECs are intended to discriminate chemicals that may contribute to toxicity from those that probably contribute to toxicity (i.e., effects are more likely than not). Thus, it is important to limit the chances of incorrectly identifying a chemical as being of concern. 
Table 4. Summary of selected toxicity test- and screening level concentration-based sediment quality benchmarks for freshwater sediments ${ }^{a}$

\begin{tabular}{|c|c|c|c|c|c|}
\hline \multirow[b]{2}{*}{ Chemical } & \multicolumn{3}{|c|}{$\mathbf{A R C S}^{b}$} & \multicolumn{2}{|c|}{ Ontario MOE ${ }^{c}$} \\
\hline & TEC & PEC & NEC & Low & Severe \\
\hline \multicolumn{6}{|c|}{ Inorganics (mg/kg dry weight) } \\
\hline Aluminum & & 58030 & 73160 & & \\
\hline Arsenic & 12.1 & 57 & 92.9 & 6 & 33 \\
\hline Cadmium & 0.592 & 11.7 & 41.1 & 0.6 & 10 \\
\hline Chromium & 56 & 159 & 312 & 26 & 110 \\
\hline Copper & 28 & 77.7 & 54.8 & 16 & 110 \\
\hline Iron & & & & $2 \%$ & $4 \%$ \\
\hline Lead & 34.2 & 396 & 68.7 & 31 & 250 \\
\hline Manganese & 1673 & 1081 & 819 & 460 & 1110 \\
\hline Mercury & & & & 0.2 & 2 \\
\hline Nickel & 39.6 & 38.5 & 37.9 & 16 & 75 \\
\hline Zinc & 159 & 1532 & 541 & 120 & 820 \\
\hline \multicolumn{6}{|c|}{ Organics $(\mu \mathrm{g} / \mathrm{kg}$ dry weight) } \\
\hline Aldrin & & & & 2 & 80 \\
\hline Anthracene & 31.62 & 547.72 & 1700 & 220 & 3700 \\
\hline Benz(a)anthracene & 260 & 4200 & 3500 & 320 & 14,800 \\
\hline Benzo(a)pyrene & 350 & 393.7 & 440 & 370 & 14,400 \\
\hline Benzo(k)fluoranthene & & & & 240 & 13,400 \\
\hline Benzo(b,k)fluoranthene & 27.2 & & 4000 & & \\
\hline Benzo(g,h,i)perylene & 290 & 6300 & 3800 & 170 & 3200 \\
\hline $\mathrm{BHC}$ & & & & 3 & 120 \\
\hline BHC, alpha- & & & & 6 & 100 \\
\hline BHC, beta- & & & & 5 & 210 \\
\hline Chlordane & & & & 7 & 60 \\
\hline Chrysene & 500 & 5200 & 4000 & 340 & 4600 \\
\hline DDD, p,p'- & & & & 8 & 60 \\
\hline DDE, p,p'- & & & & 5 & 190 \\
\hline DDT, o,p'- + p,p'- & & & & 8 & 710 \\
\hline DDT, Total ${ }^{d}$ & & & & 7 & 120 \\
\hline Dibenzo(a,h)anthracene & & 28.2 & 870 & 60 & 1300 \\
\hline Dieldrin & & & & 2 & 910 \\
\hline Endrin & & & & 3 & 1300 \\
\hline Fluoranthene & 64.23 & 834.27 & 7500 & 750 & 10,200 \\
\hline Fluorene & 34.64 & 651.92 & 1800 & 190 & 1600 \\
\hline $\mathrm{HCB}$ & & & & 20 & 240 \\
\hline Heptachlor epoxide & & & & $5^{e}$ & $50^{f}$ \\
\hline Indeno(1,2,3-c,d)pyrene & 78 & 836.66 & 3800 & 200 & 3200 \\
\hline Lindane (gamma-BHC) & & & & $3^{e, g}$ & $10^{f, g}$ \\
\hline Mirex & & & & 7 & 1300 \\
\hline Naphthalene & 32.75 & 687.39 & 290 & & \\
\hline PAH, Total LMW & 786 & 3369 & 3040 & & \\
\hline PAH, Total HMW & 2900 & 4353.82 & 51000 & & \\
\hline PAH, Total & 3553 & 13660 & 84600 & 4000 & 100,000 \\
\hline PCB, Total & 31.62 & 244.66 & 194 & $70^{g}$ & $5300^{g}$ \\
\hline
\end{tabular}


Table 4 (continued)

\begin{tabular}{|c|c|c|c|c|c|}
\hline \multirow[b]{2}{*}{ Chemical } & \multicolumn{3}{|c|}{$\mathbf{A R C S}^{b}$} & \multicolumn{2}{|c|}{ Ontario MOE ${ }^{c}$} \\
\hline & TEC & PEC & NEC & Low & Severe \\
\hline $\mathrm{PCB}, 1016$ & & & & $7^{e, g}$ & $530^{f, g}$ \\
\hline PCB, 1248 & & & & $30^{e, g}$ & $1500^{f, g}$ \\
\hline PCB, 1254 & & & & $60^{e, g}$ & $340^{f, g}$ \\
\hline PCB, 1260 & & & & $5^{e, g}$ & $240^{f, g}$ \\
\hline Phenanthrene & & & & 560 & 9500 \\
\hline Pyrene & 570 & 3225 & 6100 & 490 & 8500 \\
\hline
\end{tabular}

${ }^{a}$ Benchmark values are generally presented herein with the same number of significant digits used in the source document.

${ }^{b}$ ARCS $=$ Assessment and Remediation of Contaminated Sediments Program; TEC $=$ Threshold Effect Concentration, $\mathrm{PEC}=$ Probable Effect Concentration; and NEC = high No Effect Concentration from EPA (1996).

${ }^{c}$ Ontario MOE = Ontario Ministry of the Environment; Low = lowest effect level and is the 5th percentile of the screening level concentration, except where noted otherwise; Severe = severe effect level and is the 95th percentile of the screening level concentration, except where noted otherwise; source document is Persaud et al. (1993); values for organic chemicals were normalized assuming $1 \%$ total organic carbon.

${ }^{d}$ Total DDT is the sum of the concentrations of the o,p'- and p,p'- isomers of DDD, DDE, and DDT.

${ }^{e} 10$ th percentile of the screening level concentration.

${ }^{f} 90$ th percentile of the screening level concentration.

${ }^{g}$ Denotes tentative guideline.

For these same reasons, the ranking process emphasized maximizing the \% Total Correct for all benchmarks, minimizing the \% False Negatives for TECs, and minimizing the \% False Positives for PECs and NECs. A score was calculated for each benchmark that met the minimum requirements for recommendation. The score for a TEC was the $\%$ Total Correct minus the $\%$ False Negatives (i.e., Score $=\% \mathrm{TC}-\% \mathrm{FN}$ ). The score for a PEC or NEC was the \% Total Correct minus the \% False Positives(i.e., Score $=\% \mathrm{TC}-\% \mathrm{FP}$ ). The maximum possible score for any SEC was 100. That is, $100 \%$ Total Correct and 0\% False Negatives or False Positives. The SEC with the highest score was selected as the representative benchmark. In the event of a tie score, the SEC with the highest \% Total Correct was selected. If the \% Total Correct values also were the same, then the most conservative SEC was selected (i.e., the one with the lowest concentration).

\subsubsection{SLC Benchmarks}

The Ontario Ministry of the Environment (Ontario MOE) has prepared provincial sediment quality guidelines using the SLC approach. These values are based on Ontario sediments and benthic species from a wide range of geographical areas within the province (Persaud et al. 1993). The lowest effect level (Low) is the level at which actual ecotoxic effects become apparent. The severe effect level (Severe) represents contaminant levels that could potentially eliminate most of the benthic organisms (Persaud et al. 1993). These "Low" and "Severe" effect values are potential SQBs and are presented in Table 4.

Although SLC-derived values are based on biological effects and are suitable for all classes of chemicals and most types of sediment, the endpoint used to derive them (species absence) is considered insensitive (MacDonald 1994). Therefore, the SLC values may not be adequately protective. A qualitative comparison of the SLC values to the NOAA and FDEP values in Table 5 suggests that the Low values may be moderately underprotective for most organics. Of the 10 Low values, 9 are approximately 2 to 10 times higher than the ER-L or TEL. However, the Low values for metals are remarkably similar to the ER-L or TEL values. Most of the Severe values for metals appear to be reasonably comparable to the ER-M or PEL, but many of the Severe values for organics are 10 to 100 times higher than the ER-M or PEL. 
One advantage to the use of the Ontario MOE values for organic chemicals is that they are normalized to $1 \%$ TOC. Therefore, these SQBs can be adjusted for site-specific OC content similarly to the adjustment made for EqP SQBs.

\subsection{EPA SCREENING VALUES}

\subsubsection{Ecotox Thresholds}

EPA's OSWER has published Ecotox Thresholds (ETs) intended to be used for screening contaminants at CERCLA sites (OSWER 1996). These values are available for 8 metals and 41 organics in sediments and are presented in Table 5; their derivation is briefly explained herein.

The preferred method for determining sediment ETs is to use the proposed SQC values (EPA 1993a-e), which are derived using the EqP method. Superfund has elected to use the lower limit of the $95 \%$ confidence interval as the ET, rather than the central tendency value, to maintain an appropriate level of conservatism for screening purposes (OSWER 1996). The SQC ETs in Table 5 are normalized to $1 \%$ TOC.

SQBs are used when SQCs are not available. The SQB is calculated in the same manner as the SQC except that a Tier II Secondary Chronic Value is used. Four of these are from the Great Lakes Water Quality Initiative (EPA 1992), 12 are from Suter and Mabrey (1994), and 17 were calculated by OSWER (1996). Three chemicals with OSWER-derived Secondary Chronic Values (endosulfan, methoxyclor, and malathion) had NAWQCs, but the criteria were judged to be old and unreliable. Tier II values were not derived if no daphnia acute values were available. The SQB ETs in Table 5 are normalized to $1 \%$ TOC.

The ER-L value is used if neither an SQC nor an SQB was available. OSWER noted that there is relatively low correlation between the incidence of effects and the ER-Ls for mercury, nickel, total PCBs, and DDT (Long et al. 1995) and that the ETs for these four chemicals should be used cautiously.

\subsubsection{Region IV Screening Values}

EPA Region IV has published ecological screening values for sediments (Region IV 1995); they are presented in Table 5. The selected effect level is the lower of the ER-L (Long et al. 1995) and TEL (MacDonald 1994). The ER-L for antimony is from Long and Morgan (1990). When the Contract Laboratory Program's Practical Quantitation Limit (PQL) is above the effect level, the screening value defaults to the PQL. However, if concentrations below the PQL are reported, they should be compared with the effect level. 
Table 5. EPA Region IV and OSWER sediment screening values ${ }^{a}$

\begin{tabular}{|c|c|c|c|c|}
\hline \multirow[b]{2}{*}{ Chemical } & \multicolumn{2}{|c|}{ Region IV ${ }^{b}$} & \multicolumn{2}{|c|}{ OSWER $^{c}$} \\
\hline & Value & Type $^{d}$ & Value & Type $^{e}$ \\
\hline \multicolumn{5}{|c|}{ Inorganics (mg/kg dry weight) } \\
\hline Antimony & 12 & PQL & & \\
\hline Arsenic & 7.24 & TEL & 8.2 & ER-L \\
\hline Cadmium & 1 & PQL & 1.2 & ER-L \\
\hline Chromium & 52.3 & TEL & 81 & ER-L \\
\hline Copper & 18.7 & TEL & 34 & ER-L \\
\hline Lead & 30.2 & TEL & 47 & ER-L \\
\hline Mercury & 0.13 & TEL & 0.15 & ER-L \\
\hline Nickel & 15.9 & ER-L & 21 & ER-L \\
\hline Silver & 2 & PQL & & \\
\hline Zinc & 124 & TEL & 150 & ER-L \\
\hline \multicolumn{5}{|c|}{ Organics $(\mu \mathrm{g} / \mathrm{kg}$ dry weight) } \\
\hline Acenaphthene & 330 & PQL & 620 & SQC \\
\hline Acenaphthylene & 330 & PQL & & \\
\hline Anthracene & 330 & PQL & & \\
\hline Benzene & & & 57 & SQB \\
\hline Benzo(a)anthracene & 330 & PQL & & \\
\hline Benzo(a)pyrene & 330 & PQL & 430 & ER-L \\
\hline Biphenyl & & & 1100 & SQB \\
\hline Bis(2-ethylhexyl)phthalate & 182 & TEL & & \\
\hline 4-Bromophenyl phenyl ether & & & 1300 & SQB \\
\hline Butylbenzyl phthalate & & & 11,000 & SQB \\
\hline Chlordane & 1.7 & PQL & & \\
\hline Chlorobenzene & & & 820 & SQB \\
\hline Chrysene & 330 & PQL & & \\
\hline DDD & 3.3 & PQL & & \\
\hline DDD, p,p'- & 3.3 & PQL & & \\
\hline DDE & 3.3 & PQL & & \\
\hline DDT & 3.3 & PQL & & \\
\hline DDT, p,p'- & 3.3 & PQL & & \\
\hline DDT, Totalf & 3.3 & PQL & 1.6 & ER-L \\
\hline Diazinon & & & 1.9 & SQB \\
\hline Dibenzofuran & & & 2000 & SQB \\
\hline
\end{tabular}


21

Table 5 (continued)

\begin{tabular}{|c|c|c|c|c|}
\hline \multirow[b]{2}{*}{ Chemical } & \multicolumn{2}{|c|}{ Region $\mathbf{I V}^{b}$} & \multicolumn{2}{|c|}{ OSWER $^{c}$} \\
\hline & Value & Type $^{d}$ & Value & Type $^{e}$ \\
\hline Dibenzo(a,h)anthracene & 330 & PQL & & \\
\hline 1,2-Dichlorobenzene & & & 340 & SQB \\
\hline 1,3-Dichlorobenzene & & & 1700 & SQB \\
\hline 1,4-Dichlorobenzene & & & 350 & SQB \\
\hline Dieldrin & 3.3 & PQL & 52 & SQC \\
\hline Diethyl phthalate & & & 630 & SQB \\
\hline Di-n-butylphthalate & & & 11,000 & SQB \\
\hline Endosulfan, mixed isomers & & & 5.4 & SQB \\
\hline Endosulfan, alpha- & & & 2.9 & SQB \\
\hline Endosulfan, beta- & & & 14 & SQB \\
\hline Endrin & 3.3 & PQL & 20 & SQC \\
\hline Ethylbenzene & & & 3600 & SQB \\
\hline Fluoranthene & 330 & PQL & 2900 & SQC \\
\hline Fluorene & 330 & PQL & & \\
\hline Hexachloroethane & & & 1000 & SQB \\
\hline Lindane (gamma HCH) & 3.3 & PQL & 3.7 & SQB \\
\hline Malathion & & & 0.67 & SQB \\
\hline Methoxychlor & & & 19 & SQB \\
\hline 2-Methyl naphthalene & 330 & PQL & & \\
\hline Naphthalene & 330 & PQL & 480 & SQB \\
\hline PAHs, Total LMW ${ }^{g}$ & 330 & PQL & & \\
\hline PAHs, Total HMW ${ }^{g}$ & 655 & TEL & & \\
\hline PAHs, Total ${ }^{g}$ & 1684 & TEL & 4000 & ER-L \\
\hline PCBs, Total & 33 & PQL & 23 & ER-L \\
\hline Phenanthrene & 330 & PQL & 850 & SQC \\
\hline Pyrene & 330 & PQL & 660 & ER-L \\
\hline 1,1,2,2-Tetrachloroethane & & & 940 & SQB \\
\hline Tetrachloroethylene & & & 530 & SQB \\
\hline Tetrachloromethane & & & 1200 & SQB \\
\hline Toluene & & & 670 & SQB \\
\hline Toxaphene & & & 28 & SQB \\
\hline Tribromomethane & & & 650 & SQB \\
\hline
\end{tabular}


Table 5 (continued)

\begin{tabular}{|c|c|c|c|c|}
\hline \multirow[b]{2}{*}{ Chemical } & \multicolumn{2}{|c|}{ Region $I^{b}$} & \multicolumn{2}{|c|}{ OSWER $^{c}$} \\
\hline & Value & Type $^{d}$ & Value & Type $^{e}$ \\
\hline 1,2,4-Trichlorobenzene & & & 9200 & SQB \\
\hline 1,1,1-Trichloroethane & & & 170 & SQB \\
\hline Trichloroethylene & & & 1600 & SQB \\
\hline -Xylene & & & 25 & SQB \\
\hline
\end{tabular}

${ }^{a}$ Screening values are presented herein with the same number of significant digits used in the EPA source documents.

${ }^{b}$ Reg IV = EPA Region IV ecological screening values for sediments (Region IV 1995) and is either the selected sediment

effects value or the PQL, whichever is greater. The selected effects value is the lower of the ER-L and TEL.

${ }^{c}$ OSWER = EPA Office of Solid Waste and Emergency Response Ecotox Thresholds (ET). Only the most preferred ET, as defined in OSWER (1996), is presented.

${ }^{d} \mathrm{ER}-\mathrm{L}=$ effects range-low and, except where noted otherwise, is from Long et al. (1995); TEL = threshold effects level and is from MacDonald (1994); $\mathrm{PQL}=$ Contract Laboratory Program's practical quantification limit.

${ }^{e} \mathrm{ER}-\mathrm{L}=$ is the same as for Reg IV values; SQC = the lower limit of the 95 percent confidence interval of the proposed EPA sediment quality criteria, assuming one percent total organic carbon; SQB = the EPA sediment quality benchmark based EPA Tier II Chronic value (Region IV 1996), assuming one percent total organic carbon.

${ }^{f}$ Total DDT is the sum of the concentrations of the o,p'- and p,p'- isomers of DDD, DDE, and DDT.

LMW = low molecular weight and is the sum of the concentrations of acenaphthene, acenaphthylene, anthracene, fluorene, 2-methylnaphthalene, naphthalene, and phenanthrene; HMW = high molecular weight and is the sum of the concentrations of benz(a)anthracene, benzo(a)pyrene, chrysene, dibenzo(a,h)anthracene, fluoranthene, and pyrene; Total is the sum of the concentrations of the aforementioned low and high molecular weight PAHs.

\subsection{BACKGROUND CONCENTRATIONS}

Background sediment concentrations should be used as a check for the metals benchmarks. This is because some of these benchmarks are quite conservative, and because the measured concentrations in ambient sediment may include forms that are not bioavailable, benchmark concentrations may be lower than background sediment concentrations. If the background concentrations are valid and represent an uncontaminated state and if the exposure site does not contain forms of the chemicals that are more bioavailable or toxic than the forms at background sites, then screening benchmarks lower than the background concentration should not be used.

\section{BENCHMARK USE IN BASELINE ECOLOGICAL RISK ASSESSMENTS}

To evaluate ecological effects of contaminated sediments for a baseline ERA, it is recommended that sediment be collected for toxicity testing and the benthic macroinvertebrate community be surveyed. This is important because chemical concentrations are not accurate predictors of biological and ecological effects. This is because the percentage of the chemical that is bioavailable may range from 0 to $100 \%$ (Burton and Scott 1992). Benchmarks may be used to determine which chemicals present in the sediment are most likely causing the toxicity. Use of a weight-of-evidence approach enables a more accurate evaluation of adverse ecological impact. 


\section{CHEMICAL-SPECIFIC CONSIDERATIONS}

Chapters 2 and 3 address the general considerations associated with using sediment benchmarks to evaluate the various chemical types (e.g., metals, nonionic organics, polar organics, ionic organics). The following text addresses chemical-specific information that should be considered when using these benchmarks, with a focus on the reliability of a benchmark for a given chemical. The chemical-specific considerations associated with WQBs used in the EqP SQBs are discussed in Suter and Tsao (1996). MacDonald (1994) and Long et al. (1995) discussed the degree of reliability associated with the FDEP and NOAA values for each chemical. However, a chemical-by-chemical evaluation of the Ontario MOE values was not available (Persaud et al. 1993). A chemical-by-chemical evaluation of the ARCS values is not presented here because the measures of reliability for each chemical and SEC combination were incorporated into the process of selecting a representative benchmark (Chap. 3). These benchmarks can be further evaluated by critically reviewing the information presented in Table A.1.

Reliability of the NOAA and FDEP values is a function of the agreement between the predicted and observed incidence of effects (Long et al. 1995; MacDonald 1994). Reliability of the TEL is low if $>25 \%$ of the concentrations below the TEL were associated with effects (i.e., the number of "hits" below the TEL divided by the total number of concentrations below the TEL is $>0.25$ ). On the basis of this criterion, a TEL with low reliability may be underprotective and caution should be used when attempting to exclude that chemical as a chemical of potential ecological concern. Reliability of the PEL is low if $<50 \%$ of the concentrations above the PEL were associated with effects. Therefore, a PEL with low reliability may overpredict the potential for real effects; this is primarily of concern when the SQBs are used in baseline assessments to help predict the magnitude of effects and help determine causality of observed effects.

The designations by Long et al. (1995) (relatively high reliability and lower reliability) were somewhat different than the designations by MacDonald (1994) (low, moderate, and high). The designation of low reliability also is used herein for the ER-Ls and ER-Ms, because SQBs of low reliability are of particular concern. Reliability is considered low if the incidence of effects is $>25 \%$ at concentrations below the ER-L. Reliability of the ER-M is considered low if the incidence of effects is $<50 \%$ at concentrations above the ER-M. Other factors (e.g., concordance of effects) also were considered by MacDonald (1994) and Long et al. (1995) to determine the overall reliability of the FDEP and NOAA values, respectively. These determinations also are presented in the following text, where appropriate.

\subsection{METALS}

Antimony - Data are available from only two geographic regions (Puget Sound/Commencement Bay and San Francisco Bay); therefore, the degree of confidence in the NOAA values is moderate (Long and Morgan 1991). No criteria are available for comparison from FDEP or Ontario MOE.

Arsenic - Confidence in the TEL and ER-L is high and relatively high, respectively. Confidence in the ER-M is somewhat lower, and confidence in the PEL is Low. Therefore, the TEL and ER-L appear to be reliable indicators of the threshold for effects, and the ER-M appears to be the better indicator of the level above which real effects are likely. 
Cadmium - A relatively large amount of data exists for cadmium, including spiked-sediment toxicity tests and EqP-based assessments (MacDonald et al. 1994). Klapow and Lewis (1979) calculated a statistically significant difference in the medians of acute aqueous toxicity data from saltwater and freshwater organisms. This supports the findings of Eisler (1985) (as referenced in Long and Morgan 1991), who found resistance to cadmium higher among marine than freshwater species. However, the degree of confidence in the lower and upper NOAA and FDEP values is high, and these values are considered to be reliable predictors of effects.

Chromium - There are some inconsistencies in the data available for chromium, possibly because of lack of speciation information. All data were reported as total chromium, whereas the hexavalent form is more toxic than the trivalent form. There also are no supporting data from single-chemical spikedsediment toxicity tests or from the EqP approach (MacDonald et al. 1994). Overall confidence in the FDEP values, and the PEL in particular, is moderate. Although the overall confidence in the NOAA values is relatively high, Long et al. (1995) cautioned that the incidence of effects may be unduly exaggerated by data from multiple tests performed in only two studies. On the basis of the available evaluations, the TEL and ER-L appear to be reliable predictors of the threshold for effects.

Copper-Considerable data exist for copper in sediments, and a relatively high degree of overall confidence exists for the NOAA values. Overall confidence in the FDEP values, and the PEL in particular, is moderate only. However, the TEL is considered to be a highly reliable predictor of the threshold for effects.

Iron-The only available benchmarks are the Ontario MOE Low and Severe effect levels. Although the reliability of these data was not addressed (Persaud et al. 1993), the Ontario MOE guidelines were derived for freshwater sediments. Therefore, these values appear to warrant a moderate degree of confidence.

Lead-Considerable data exist for lead in sediments, and a relatively high degree of overall confidence exists for the NOAA values. Overall confidence in the FDEP values, and the PEL in particular, is moderate only. However, the TEL is considered to be a reliable predictor of the threshold for effects. This is consistent with expected reliability of the ER-L and ER-M values. Although a relatively large amount of data exist for lead, there were no spiked-sediment toxicity test data to confirm the toxic concentrations (MacDonald et al. 1994).

Manganese-The only available benchmarks are the Ontario MOE Low and Severe effect levels. Although the reliability of these data was not addressed (Persaud et al. 1993), the Ontario MOE guidelines were derived for freshwater sediments. Therefore, these values appear to warrant a moderate degree of confidence.

Mercury - Considerable data exist for mercury, though only total mercury concentrations were reported in the data set (MacDonald et al. 1994). Confidence in the TEL and ER-L is high and relatively high, respectively. Therefore, the lower screening values should be at least conservative predictors of the threshold for effects. The PEL and ER-M may significantly overpredict the likelihood of real effects, given that confidence in these values is Low. In addition, the overall confidence in the FDEP values is low.

Nickel-Toxicity of nickel is greatly influenced by water hardness and salinity (Long and Morgan 1991). Data were from marine and estuarine field studies only, and no spiked-sediment toxicity tests or EqP approaches were used (MacDonald et al. 1994). Confidence in the TEL and ER-L is high and relatively high, respectively. Therefore, the lower screening values should be at least conservative 
predictors of the threshold for effects. The PEL and ER-M may significantly overpredict the likelihood of real effects, given that confidence in these values is Low.

Silver-A moderate amount of data is available for silver in sediments, although data exist from spiked-sediment toxicity tests or from EqP approaches (MacDonald et al. 1994). The FDEP and NOAA values hold moderate and relatively high overall confidence, respectively. These data suggest that the ER-L and TEL are likely to be reliable predictors of the threshold for effects. The ER-M is likely to be a better predictor of real effects because confidence in the PEL is Low.

Zinc - Considerable data exist for zinc in sediments, including spiked-sediment toxicity tests and EqP-based assessments (MacDonald et al. 1994). Overall confidence in the FDEP values, and the PEL in particular, is moderate only. However, the TEL is considered to be a reliable predictor of the threshold for effects. This is consistent with expected reliability of the NOAA values.

\subsection{ORGANICS}

Polycyclic aromatic hydrocarbons (PAHs) - The reliability of the individual TELs and PELs ranged from moderate to high, as did overall reliability of the FDEP values. The TELs and PELs may be somewhat overprotective for four PAHs [i.e., acenaphthene, acenaphthylene, fluorene, benz(a)anthracene, dibenzo(a,h)anthracene, and total high molecular weight polyaromatic hydrocarbons] for which the overall FDEP or ER-M values are considered moderately reliable. The TELs for fluorene and dibenzo(a,h)anthracene are considered to be only moderately reliable predictors of the threshold for effects. The TELs and PELs should be reasonably reliable predictors of the likelihood of effects for the remaining PAHs. Reliability of the ER-Ls for anthracene and fluorene is low, while reliability of the ER-M for dibenzo(a,h)anthracene is relatively low. The reliability of the ER-Ls and ER-Ms for the remaining PAHs is relatively high.

Total polychlorinated biphenyls (PCBs) - The overall reliability of the FDEP values was low, and the reliability of the TEL and PEL was only moderate. Reliability of the ER-M is considered to be relatively low. Concordance of the concentrations and effects was not high for either the NOAA or FDEP values. This may be the result of insufficiently detailed chemical information. That is, the mixture of PCB congeners may have varied considerably among sites and studies, but this information was unavailable or not included in the NOAA and FDEP analyses. Caution should be used when screening PCBs with these benchmarks.

Pesticides-The overall reliability of the FDEP values was low for chlordane, total DDT, and lindane and moderate for dieldrin and the p,p' isomers of DDD, DDE, and DDT. The TEL for total DDT is considered to have low reliability and is likely to be a poor predictor of the threshold for effects. The PELs for chlordane, p,p'-DDD, and lindane are considered to have low reliability and are likely to overpredict the likelihood of real effects. This is also somewhat true of the PELs for the other four pesticides. NOAA values are available for only two pesticides, p,p'-DDE and total DDT, for which poor concordance of effects and concentrations was observed. This may be caused by the inclusion of relatively low EqP values, which were not based on toxicity to benthic organisms (Long et al. 1995). Therefore, the NOAA values may tend to overpredict the likelihood of effects.

Bis(2-ethylhexyl)phthalate-The overall reliability of the FDEP values was high, as was the reliability of the TEL and PEL. These values are expected to be reliable predictors of the likelihood of effects. NOAA values are not available for bis(2-ethylhexyl)phthalate. 


\section{UNCERTAINTIES/LIMITATIONS}

The EqP methodology has several uncertainties. It relies on an empirical model to compute the pore water concentration from the solid phase measurements. Therefore, an uncertainty is associated with the use of the model. In addition, uncertainty exists with respect to the $\mathrm{K}_{\mathrm{ow}}$ associated with the specific chemical because it is an experimentally determined quantity (EPA 1989a). Various types of organic matter present in sediments can have significantly different binding capacities for organic contaminants; the affinity depends in large part on the source and nature of the carbon. For example, organics associated with sediments contaminated with petroleum hydrocarbons would tend to be much less toxic than those associated with sediments whose OC is natural OC (Lee and Jones-Lee 1993).

The assumption that benthic organisms have similar sensitivities to water column species has a level of uncertainty (EPA 1993f). This may be of particular concern for tube-dwelling amphipods. The tubes tend to isolate them from the interstitial water, causing speculation that their exposure is at the sediment/water interface. Additionally, the amphipod tubes are matrices of organics and inorganics; the tube walls could sorb appreciable amounts of organic contaminants, which could alter the availability of sediment-associated contaminants to those organisms (Lee and Jones-Lee 1993).

The EqP approach is known not to work for all nonpolar organics. It is well known that many pesticides that are sorbed onto soils and sediments are in the form of "bound" pesticide residues that do not participate in equilibrium reactions with water (Lee and Jones-Lee 1993).

The aquatic benchmarks [EPA WQC for the protection of aquatic life and the aquatic benchmarks developed by Suter and Tsao (1996)] for PCBs and several polynuclear aromatic hydrocarbons are class criteria based on the cumulative concentration of all members of the class. In the derivation of sediment benchmarks using the EqP approach and the aquatic benchmarks, it is necessary to apply the class level to each member of the class individually because each has a unique $\mathrm{K}_{\mathrm{oc}}$ (Lake et al. 1990). In environments where one class member comprises the majority of the sediment burden of the class, this approach should be adequate. However, if numerous class constituents are significantly enriched, a safe threshold for the class as a whole may be exceeded even though no individual constituent violates its predicted safe level (based on the aquatic benchmark) (Pavlou 1987).

The Washington state AET, NOAA, and FDEP values have several limitations. Primarily, all or most of the data used in their derivation were based on marine and estuarine systems. These values are being applied to freshwater systems at the ORR and the Portsmouth and Paducah gaseous diffusion plants. Differences include physico-chemical characteristics of the system as well as possible differences in sensitivity of biota. Washington state, NOAA, and FDEP values are for single chemicals, although sediments containing chemical mixtures were used for their derivation. The Ontario MOE values were derived to be applicable to sediment types throughout the province of Ontario. The differences between Ontario and East Tennessee, Ohio, and Kentucky sediments and biota introduce a level of uncertainty.

The uncertainties associated with the ARCS values are similar to those for the NOAA and FDEP values. That is, the SECs also were derived using sediment samples containing chemical mixtures. Although those sediments were predominantly from freshwater systems, 11 of the 62 possible samples used in one of the three tests (28-d H. azteca) were from marine systems. However, the overlying water was only $10 \%$ saline. The freshwater sediments also were from areas other than East Tennessee, including the Great Lakes, Illinois, Minnesota, Montana, and Texas. 


\section{REFERENCES}

Adams, W. J. 1987. "Bioavailability of Neutral Lipophilic Organic Chemicals Contained on Sediments: A Review," pp. 219-244 in Fate and Effects of Sediment-Bound Chemicals in Aquatic Systems, Proceedings of the Sixth Pellston Workshop, 13-17 August 1984, Florissant, Co., eds. K. L. Dickson, A. W. Maki, and W. A. Brungs, Pergamon Press, Toronto, Ontario.

Adams, W. J., R. A. Kimerle, and J. W. Barnett, Jr. 1992. "Sediment Quality and Aquatic Life Assessments," Environ. Sci. Technol. 26(10), 1865-75.

ATSDR (Agency for Toxic Substances and Disease Registry) 1989. Toxicological Profile for Selected PCBs, ATSDR/TP-88/21, U.S. Public Health Service, Washington, D.C.

Boese, B. L., H. Lee II, D. T. Specht, R. C. Randall, and M. H. Winsor 1990. "Comparison of Aqueous and Solid-Phase Uptake for Hexachlorobenzene in the Tellinid Clam Macoma nasuta (Conrad): A Mass Balance Approach,” Environ. Toxicol. Chem. 9, 221-31.

Burton, G. A., Jr., and K. J. Scott 1992. "Sediment Toxicity Evaluations-Their Niche in Ecological Assessments," Environ. Sci. Technol. 26(11), 2068-75.

Campbell, P. G. C., and A. Tessier 1991. "Biological Availability of Metals in Sediments: Analytical Approaches," pp. 161-173 in Heavy Metals in the Environment, ed. J.-P. Vernet, Elsevier Publishing, Amsterdam.

Chapman, P. M. 1989. "Current Approaches to Developing Sediment Quality Criteria," Environ. Toxicol. Chem. 8, 589-99.

Cook, R. B. et al. 1992. Phase 1 Data Summary Report for the Clinch River Remedial Investigations: Health Risk and Ecological Risk Screening Assessment, ORNL/ER-155, Oak Ridge National Laboratory, Oak Ridge, Tenn.

Di Toro, D. M., J. D. Mahony, D. J. Hansen, K. J. Scott, A. R. Carlson, and G. T. Ankley. 1992. Acid Volatile Sulfide Predicts the Acute Toxicity of Cadmium and Nickel in Sediments. Environ. Sci. Technol. 26, 96-101.

Di Toro, D. M. 1985. "A Particle Interaction Model of Reversible Organic Chemical Sorption," Chemosphere 14(10), 1503-38.

Di Toro, D. M., L. J. Dodge, and V. C. Hand 1990. "A Model for Anionic Surfactant Sorption," Environ. Sci. Technol. 24, 1013-20.

EPA (U.S. Environmental Protection Agency) 1989a. Briefing Report to the EPA Science Advisory Board on the Equilibrium Partitioning Approach to Generating Sediment Quality Criteria, EPA 440/5-89-002, Washington, D.C.

EPA (U.S. Environmental Protection Agency) 1989b. Evaluation of the Apparent Effects Threshold (AET) Approach for Assessing Sediment Quality, Report of the Sediment Criteria Subcommittee, Science Advisory Board. SAB-EETFC-89-027. 
EPA (U.S. Environmental Protection Agency) 1992. Dermal Exposure Assessment: Principles and Applications, EPA/600/8-91/011B, Office of Research and Development, Washington, D.C.

EPA (U.S. Environmental Protection Agency) 1993a. Sediment Quality Criteria for the Protection of Benthic Organisms: Acenaphthene, EPA-822-R-93-013, Washington, D.C.

EPA (U.S. Environmental Protection Agency) 1993b. Sediment Quality Criteria for the Protection of Benthic Organisms: Dieldrin, EPA-822-R-93-015, Washington, D.C.

EPA (U.S. Environmental Protection Agency) 1993c. Sediment Quality Criteria for the Protection of Benthic Organisms: Endrin, EPA-822-R-93-016, Washington, D.C.

EPA (U.S. Environmental Protection Agency) 1993d. Sediment Quality Criteria for the Protection of Benthic Organisms: Fluoranthene, EPA-822-R-93-012, Washington, D.C.

EPA (U.S. Environmental Protection Agency) 1993e. Sediment Quality Criteria for the Protection of Benthic Organisms: Phenanthrene, EPA-822-R-93-014, Washington, D.C.

EPA (U.S. Environmental Protection Agency) 1993f. Technical Basis for Deriving Sediment Quality Criteria for Nonionic Organic Contaminants for the Protection of Benthic Organisms by Using Equilibrium Partitioning, EPA-822-R-93-011, Washington, D.C.

EPA (U.S. Environmental Protection Agency) 1994. Briefing Report to the EPA Science Advisory Board on the EqP Approach to Predicting Metal Bioavailability in Sediment and the Derivation of Sediment Quality Criteria for Metals, EPA 822/D-94/002, Washington, D.C.

EPA (U.S. Environmental Protection Agency) 1995a. Internal Report: Summary of Measured, Calculated, and Recommended Log Kow Values, Office of Water, Washington, D.C.

EPA (U.S. Environmental Protection Agency) 1995b. National Sediment Inventory: Documentation of Derivation of Freshwater Sediment Quality, Office of Water, Washington, D.C.

EPA (U.S. Environmental Protection Agency) 1996. Calculation and Evaluation of Sediment Effect Concentrations for the Amphipod Hyalella azteca and the Midge Chironomus riparius, EPA 905-R96-008, Great Lakes National Program Office, Chicago, Ill.

Ginn, T. C., and R. A. Pastorak 1992. "Assessment and Management of Contaminated Sediments in Puget Sound," pp. 371-401 in Sediment Toxicity Assessment, ed. G. A. Burton, Jr., Lewis Publishers, Boca Raton, Fla.

Hull, R. N., and G. W. Suter II 1994. Toxicological Benchmarks for Screening Potential Contaminants of Concern for Effects on Sediment-Associated Biota: 1994 Revision, ES/ER/TM-95/R1, Oak Ridge National Laboratory, Oak Ridge, Tenn.

Jones, D. S., R. N. Hull, and G. W. Suter II 1996. Toxicological Benchmarks for Screening Potential Contaminants of Concern for Effects on Sediment-Associated Biota: 1996 Revision. ES/ER/TM-95/R2, Oak Ridge National Laboratory, Oak Ridge, Tenn. 
Jones, D. S., G. W. Suter II , and R. N. Hull 1997. Toxicological Benchmarks for Screening Potential Contaminants of Concern for Effects on Sediment-Associated Biota: 1997 Revision. ES/ER/TM-95/R3, Oak Ridge National Laboratory, Oak Ridge, Tenn.

Jafvert, C. T. 1990. "Sorption of Organic Acid Compounds to Sediments: Initial Model Development," Environ. Toxicol. Chem. 9, 1259-68.

Klapow, L. A., and R. H. Lewis 1979. "Analysis of Toxicity Data for California Marine Water Quality Standards" J. Water Pollut. Control Fed. 51, 2054-70.

Lake, J. L., N. I. Rubinstein, H. Lee II, C. A. Lake, J. Heltshe, and S. Pavignano 1990. "Equilibrium Partitioning and Bioaccumulation of Sediment-Associated Contaminants by Infaunal Organisms," Environ. Toxicol. Chem. 9, 1095-1106.

Landrum, P. F., and J. A. Robbins 1990. "Bioavailability of Sediment-Associated Contaminants to Benthic Invertebrates," pp. 237-63 in Sediments: Chemistry and Toxicity of In-Place Pollutants, eds. Baudo, R., J. Giesy, and H. Muntau, Lewis Publishers, Inc. Chelsea, Mich.

Lee, G. F., and A. Jones-Lee 1993. "Problems in Use of Chemical Concentration-Based Sediment Quality Criteria for Regulating Contaminated Sediment," pp. 439-448, Preprint of paper presented at the First International Specialized Conference of Contaminated Aquatic Sediments: Historical Records, Environmental Impact, and Remediation, Milwaukee, Wis., International Association on Water Quality.

Long, E. R,. and L. G. Morgan 1991. The Potential for Biological Effects of Sediment-Sorbed Contaminants Tested in the National Status and Trends Program, NOAA Technical Memorandum NOS OMA 52, National Oceanic and Atmospheric Administration.

Long, E. R., D. D. MacDonald, S. L. Smith, and F. D. Calder 1995. "Incidence of Adverse Biological Effects within Ranges of Chemical Concentrations in Marine and Estuarine Sediments," Environmental Management 19(1), 81-97.

MacDonald, D. D. 1993. Memorandum to Clell Ford, Oak Ridge National Laboratory, Environmental Sciences Division, Oak Ridge, Tenn. Jan. 28, 1993.

MacDonald, D. D., S. L. Smith, M. P. Wong, and P. Murdoch 1992. The Development of Canadian Marine Environmental Quality Guidelines, Environment Canada Ecosystem Sciences and Evaluation Directorate, Ottawa, Ontario.

MacDonald, D. D. 1994. Approach to the Assessment of Sediment Quality in Florida Coastal Waters, Florida Department of Environmental Protection, Tallahassee, Florida.

MacDonald, D. D., B. L. Charlish, M. L. Haines, and K. Brydges 1994. Approach to the Assessment of Sediment Quality in Florida Coastal Waters: Volume 3-Supporting Documentation: Biological Effects Database for Sediment, Florida Department of Environmental Protection, Tallahassee, Fla.

Maughan, J. T. 1993. "Evaluation of Contaminants in Sediments," pp. 176-205 in Ecological Assessment of Hazardous Waste Sites, ed. J. T. Maughan, Van Nostrand Reinhold, New York. 
Neff, J. M., B. W. Cornaby, R. M. Vaga, T. C. Gulbransen, J. A. Scanlon, and D. J. Bean 1988. “An Evaluation of the Screening Level Concentration Approach for Validation of Sediment Quality Criteria for Freshwater and Saltwater Ecosystems," pp. 115-27 in Aquatic Toxicology and Hazard Assessment: 10th Volume, ASTM STP 971, ed. W. J. Adams, G. A. Chapman, and W. G. Landis, American Society for Testing and Materials, Philadelphia.

OECD (Organization for Economic Cooperation and Development) 1992. Report of the OECD Workshops on Effects Assessment of Chemicals in Sediment, Organization for Economic Cooperation and Development, OECD Environment Monographs No. 60, Paris.

OSWER (Office of Solid Waste and Emergency Response) 1996. "Ecotox thresholds," ECO Update $3(2): 1-12$.

Pavlou, S. P. 1987. "The Use of the Equilibrium Partitioning Approach in Determining Safe Levels of Contaminants in Marine Sediments," pp. 388-412 in Fate and Effects of Sediment-Bound Chemicals in Aquatic Systems, Proceedings of the Sixth Pellston Workshop, 13-17 August 1984, Florissant, Co. eds. K. L. Dickson, A. W. Maki, and W. A. Brungs, Pergamon Press, Toronto, Ontario.

Persaud, D., R. Jaagumagi, and A. Hayton August 1993. Guidelines for the Protection and Management of Aquatic Sediment Quality in Ontario, Ontario Ministry of the Environment and Energy.

Region IV (U.S. Environmental Protection Agency Region IV) 1995. Ecological screening values, Ecological Risk Assessment Bulletin No. 2, Waste Management Division, U.S. Environmental Protection Agency Region IV, Atlanta, Ga.

Shea, D. 1988. "Developing National Sediment Quality Criteria," Environ. Sci. Technol. 22(11), 1256-61.

Suter, G. W. II 1995. Guide for Performing Screening Ecological Risk Assessments at DOE Facilities, ES/ER/TM-153, Oak Ridge National Laboratory, Oak Ridge, Tenn.

Suter, G. W. II, and J. B. Mabrey 1994. Toxicological Benchmarks for Screening Potential Contaminants of Concern for Effects on Aquatic Biota: 1994 Revision, ES/ER/TM-96/R1, Oak Ridge National Laboratory, Oak Ridge, Tenn.

Suter, G. W. II, and C. L. Tsao. 1996. Toxicological Benchmarks for Screening Potential Contaminants of Concern for Effects on Aquatic Biota: 1996 Revision, ES/ER/TM-96/R2, Oak Ridge National Laboratory, Oak Ridge, Tenn. 


\section{APPENDIX \\ SUMMARY OF ALL SEDIMENT EFFECT CONCENTRATIONS THAT MEET THE MINIMUM REQUIREMENTS FOR RECOMMENDATION}


Table A.1 Summary of all sediment effect concentrations (SECs) that meet the minimum requirements for recommendation ${ }^{a}$

\begin{tabular}{|c|c|c|c|c|c|c|c|c|c|}
\hline Chemical & $\begin{array}{l}\text { BMK } \\
\text { Type }^{b} \\
\end{array}$ & Test $^{c}$ & $\mathrm{SEC}^{d}$ & Conc. & $\begin{array}{c}\text { Total } \\
\text { Correct } \\
(\%)^{e} \\
\end{array}$ & $\begin{array}{c}\text { False } \\
\text { Positives } \\
(\%)^{f} \\
\end{array}$ & $\begin{array}{c}\text { False } \\
\text { Negatives } \\
(\%)^{\mathrm{g}}\end{array}$ & Score $^{h}$ & $\begin{array}{c}\text { Selected } \\
\text { BMK }^{i} \\
\end{array}$ \\
\hline \multicolumn{10}{|c|}{ Inorganics (mg/kg) } \\
\hline Aluminum & PEC & HA28 & ERM & 58030 & 64 & 16 & 20 & 48 & $\mathrm{x}$ \\
\hline Aluminum & PEC & HA28 & PEL & 59572.012 & 52 & 16 & 32 & 36 & \\
\hline Aluminum & NEC & HA28 & NEC & 73160 & 52 & 4 & 44 & 48 & $\mathrm{x}$ \\
\hline Arsenic & TEC & HA14 & ERL & 12.1 & 69 & 25 & 6 & 63 & $\mathrm{x}$ \\
\hline Arsenic & TEC & HA14 & TEL & 11.24478 & 66 & 28 & 6 & 60 & \\
\hline Arsenic & TEC & HA28 & TEL & 10.79768 & 62 & 27 & 12 & 50 & \\
\hline Arsenic & TEC & CR14 & ERL & 32 & 60 & 31 & 10 & 50 & \\
\hline Arsenic & TEC & HA28 & ERL & 13.1 & 63 & 21 & 15 & 48 & \\
\hline Arsenic & TEC & CR14 & TEL & 21.76235 & 55 & 36 & 10 & 45 & \\
\hline Arsenic & PEC & CR14 & ERM & 57 & 71 & 10 & 19 & 61 & $\mathrm{x}$ \\
\hline Arsenic & PEC & CR14 & PEL & 54.02222 & 69 & 12 & 19 & 57 & \\
\hline Arsenic & PEC & HA28 & PEL & 48.38512 & 63 & 6 & 31 & 57 & \\
\hline Arsenic & PEC & HA28 & ERM & 49.6 & 63 & 6 & 31 & 57 & \\
\hline Arsenic & PEC & HA14 & ERM & 33 & 66 & 13 & 22 & 53 & \\
\hline Arsenic & PEC & HA14 & PEL & 39.46644 & 63 & 13 & 25 & 50 & \\
\hline Arsenic & NEC & HA14 & NEC & 92.9 & 59 & 3 & 38 & 56 & $\mathrm{x}$ \\
\hline Arsenic & NEC & HA28 & NEC & 102 & 54 & 2 & 44 & 52 & \\
\hline Cadmium & TEC & HA14 & TEL & 0.59161 & 81 & 19 & 0 & 81 & $\mathrm{x}$ \\
\hline Cadmium & TEC & HA14 & ERL & 0.7 & 81 & 19 & 0 & 81 & \\
\hline Cadmium & TEC & CR14 & ERL & 9.1 & 86 & 2 & 12 & 74 & \\
\hline Cadmium & TEC & CR14 & TEL & 2.89344 & 69 & 21 & 10 & 59 & \\
\hline Cadmium & TEC & HA28 & TEL & 0.58327 & 66 & 26 & 8 & 58 & \\
\hline Cadmium & TEC & HA28 & ERL & 0.7 & 66 & 26 & 8 & 58 & \\
\hline Cadmium & PEC & CR14 & ERM & 11.7 & 81 & 2 & 17 & 79 & $\mathrm{x}$ \\
\hline Cadmium & PEC & HA14 & PEL & 3.2249 & 78 & 3 & 19 & 75 & \\
\hline Cadmium & PEC & CR14 & PEL & 6.62382 & 81 & 7 & 12 & 74 & \\
\hline Cadmium & PEC & HA14 & ERM & 5.2 & 75 & 3 & 22 & 72 & \\
\hline Cadmium & PEC & HA28 & PEL & 3.24654 & 74 & 5 & 21 & 69 & \\
\hline Cadmium & PEC & HA28 & ERM & 3.875 & 71 & 5 & 24 & 66 & \\
\hline Cadmium & NEC & CR14 & NEC & 41.1 & 74 & 2 & 24 & 72 & $\mathrm{x}$ \\
\hline Cadmium & NEC & HA14 & NEC & 8 & 72 & 3 & 25 & 69 & \\
\hline Cadmium & NEC & HA28 & NEC & 8 & 71 & 2 & 27 & 69 & \\
\hline Chromium & TEC & HA14 & ERL & 56 & 81 & 13 & 6 & 75 & $\mathrm{x}$ \\
\hline Chromium & TEC & HA14 & TEL & 47.91659 & 66 & 28 & 6 & 60 & \\
\hline Chromium & TEC & CR14 & ERL & 39.3 & 62 & 36 & 2 & 60 & \\
\hline Chromium & TEC & CR14 & TEL & 39.79686 & 60 & 36 & 5 & 55 & \\
\hline Chromium & TEC & HA28 & TEL & 36.28636 & 60 & 26 & 15 & 45 & \\
\hline Chromium & TEC & HA28 & ERL & 38.5 & 60 & 26 & 15 & 45 & \\
\hline Chromium & PEC & CR14 & PEL & 159.4051 & 86 & 2 & 12 & 84 & $\mathrm{x}$ \\
\hline Chromium & PEC & CR14 & ERM & 363 & 83 & 0 & 17 & 83 & \\
\hline Chromium & PEC & HA14 & PEL & 130.9217 & 81 & 0 & 19 & 81 & \\
\hline Chromium & PEC & HA14 & ERM & 293 & 78 & 0 & 22 & 78 & \\
\hline Chromium & PEC & HA28 & PEL & 119.365 & 73 & 0 & 27 & 73 & \\
\hline Chromium & PEC & HA28 & ERM & 274 & 73 & 0 & 27 & 73 & \\
\hline
\end{tabular}


A-4

Table A.1 (continued)

\begin{tabular}{|c|c|c|c|c|c|c|c|c|c|}
\hline Chemical & $\begin{array}{l}\text { BMK } \\
\text { Type }^{b} \\
\end{array}$ & Test $^{c}$ & $\mathrm{SEC}^{d}$ & Conc. & $\begin{array}{c}\text { Total } \\
\text { Correct } \\
(\%)^{e}\end{array}$ & $\begin{array}{c}\text { False } \\
\text { Positives } \\
(\%)^{f} \\
\end{array}$ & $\begin{array}{c}\text { False } \\
\text { Negatives } \\
(\%)^{\mathrm{g}}\end{array}$ & Score $^{h}$ & $\begin{array}{c}\text { Selected } \\
\text { BMK }^{i} \\
\end{array}$ \\
\hline Chromium & NEC & CR14 & NEC & 312 & 83 & 2 & 14 & 81 & $\mathrm{x}$ \\
\hline Chromium & NEC & HA14 & NEC & 95 & 81 & 3 & 16 & 78 & \\
\hline Chromium & NEC & HA28 & NEC & 95 & 73 & 2 & 26 & 71 & \\
\hline Copper & TEC & HA14 & TEL & 28.0125 & 84 & 13 & 3 & 81 & $\mathrm{x}$ \\
\hline Copper & TEC & HA14 & ERL & 41.3 & 81 & 13 & 6 & 75 & \\
\hline Copper & TEC & HA28 & ERL & 41.3 & 73 & 15 & 12 & 61 & \\
\hline Copper & TEC & HA28 & TEL & 28.0125 & 71 & 19 & 10 & 61 & \\
\hline Copper & TEC & CR14 & TEL & 67.4535 & 64 & 26 & 10 & 54 & \\
\hline Copper & TEC & CR14 & ERL & 96.5 & 64 & 26 & 10 & 54 & \\
\hline Copper & PEC & HA14 & PEL & 77.71197 & 81 & 0 & 19 & 81 & $\mathrm{x}$ \\
\hline Copper & PEC & HA14 & ERM & 122.25 & 78 & 0 & 22 & 78 & \\
\hline Copper & PEC & HA28 & PEL & 101.2304 & 71 & 8 & 21 & 63 & \\
\hline Copper & PEC & HA28 & ERM & 187 & 69 & 6 & 25 & 63 & \\
\hline Copper & PEC & CR14 & ERM & 206.5 & 62 & 21 & 17 & 41 & \\
\hline Copper & PEC & CR14 & PEL & 291.3271 & 60 & 19 & 21 & 41 & \\
\hline Copper & NEC & HA14 & NEC & 54.8 & 81 & 3 & 16 & 78 & $\mathrm{x}$ \\
\hline Copper & NEC & HA28 & NEC & 583 & 56 & 2 & 42 & 54 & \\
\hline Manganese & TEC & CR14 & ERL & 1673 & 82 & 8 & 11 & 71 & $\mathrm{x}$ \\
\hline Manganese & TEC & HA14 & ERL & 726 & 83 & 4 & 13 & 70 & \\
\hline Manganese & TEC & CR14 & TEL & 1079.077 & 79 & 11 & 11 & 68 & \\
\hline Manganese & TEC & HA14 & TEL & 614.7219 & 67 & 25 & 8 & 59 & \\
\hline Manganese & TEC & HA28 & ERL & 726 & 68 & 11 & 20 & 48 & \\
\hline Manganese & TEC & HA28 & TEL & 631.3272 & 59 & 25 & 16 & 43 & \\
\hline Manganese & PEC & HA14 & PEL & 1080.689 & 75 & 0 & 25 & 75 & $\mathrm{x}$ \\
\hline Manganese & PEC & CR14 & PEL & 1538.382 & 82 & 8 & 11 & 74 & \\
\hline Manganese & PEC & CR14 & ERM & 2410 & 79 & 5 & 16 & 74 & \\
\hline Manganese & PEC & HA14 & ERM & 1678 & 71 & 0 & 29 & 71 & \\
\hline Manganese & PEC & HA28 & PEL & 1184.756 & 61 & 5 & 34 & 56 & \\
\hline Manganese & PEC & HA28 & ERM & 1673 & 59 & 5 & 36 & 54 & \\
\hline Manganese & NEC & HA14 & NEC & 819 & 71 & 4 & 25 & 67 & $\mathrm{x}$ \\
\hline Nickel & TEC & HA14 & ERL & 39.6 & 94 & 0 & 6 & 88 & $\mathrm{x}$ \\
\hline Nickel & TEC & CR14 & ERL & 40 & 93 & 2 & 5 & 88 & \\
\hline Nickel & TEC & HA14 & TEL & 27.71714 & 81 & 16 & 3 & 78 & \\
\hline Nickel & TEC & CR14 & TEL & 26.60827 & 76 & 19 & 5 & 71 & \\
\hline Nickel & TEC & HA28 & ERL & 23.8 & 68 & 13 & 19 & 49 & \\
\hline Nickel & TEC & HA28 & TEL & 19.5141 & 65 & 18 & 18 & 47 & \\
\hline Nickel & PEC & HA14 & PEL & 38.49675 & 94 & 0 & 6 & 94 & $\mathrm{x}$ \\
\hline Nickel & PEC & CR14 & PEL & 38.68139 & 90 & 5 & 5 & 85 & \\
\hline Nickel & PEC & CR14 & ERM & 47.5 & 83 & 2 & 14 & 81 & \\
\hline Nickel & PEC & HA14 & ERM & 47.5 & 78 & 0 & 22 & 78 & \\
\hline Nickel & PEC & HA28 & ERM & 44.7 & 73 & 0 & 27 & 73 & \\
\hline Nickel & PEC & HA28 & PEL & 32.82179 & 74 & 5 & 21 & 69 & \\
\hline Nickel & NEC & HA14 & NEC & 37.9 & 91 & 3 & 6 & 88 & $\mathrm{x}$ \\
\hline Nickel & NEC & CR14 & NEC & 57 & 79 & 2 & 19 & 77 & \\
\hline Nickel & NEC & HA28 & NEC & 43 & 73 & 2 & 26 & 71 & \\
\hline Lead & TEC & HA14 & TEL & 34.17455 & 84 & 13 & 3 & 81 & $\mathrm{x}$ \\
\hline
\end{tabular}


A-5

Table A.1 (continued)

\begin{tabular}{|c|c|c|c|c|c|c|c|c|c|}
\hline Chemical & $\begin{array}{l}\text { BMK } \\
\text { Type }^{b}\end{array}$ & Test $^{c}$ & $\mathrm{SEC}^{d}$ & Conc. & $\begin{array}{c}\text { Total } \\
\text { Correct } \\
(\%)^{e} \\
\end{array}$ & $\begin{array}{c}\text { False } \\
\text { Positives } \\
(\%)^{f}\end{array}$ & $\begin{array}{c}\begin{array}{c}\text { False } \\
\text { Negatives } \\
(\%)^{\mathrm{g}}\end{array} \\
\end{array}$ & Score $^{h}$ & $\begin{array}{c}\text { Selected } \\
\text { BMK }^{i} \\
\end{array}$ \\
\hline Lead & TEC & CR14 & ERL & 99 & 83 & 7 & 10 & 73 & \\
\hline Lead & TEC & HA14 & ERL & 51 & 78 & 13 & 9 & 69 & \\
\hline Lead & TEC & CR14 & TEL & 69.64912 & 74 & 21 & 5 & 69 & \\
\hline Lead & TEC & HA28 & ERL & 55 & 74 & 15 & 11 & 63 & \\
\hline Lead & TEC & HA28 & TEL & 37.22902 & 71 & 21 & 8 & 63 & \\
\hline Lead & PEC & CR14 & ERM & 396 & 81 & 2 & 17 & 79 & $\mathrm{x}$ \\
\hline Lead & PEC & HA14 & PEL & 117.4947 & 78 & 0 & 22 & 78 & \\
\hline Lead & PEC & HA14 & ERM & 251 & 78 & 0 & 22 & 78 & \\
\hline Lead & PEC & CR14 & PEL & 191.803 & 81 & 5 & 14 & 76 & \\
\hline Lead & PEC & HA28 & PEL & 81.74344 & 77 & 6 & 16 & 71 & \\
\hline Lead & PEC & HA28 & ERM & 98.7 & 74 & 3 & 23 & 71 & \\
\hline Lead & NEC & HA14 & NEC & 68.7 & 84 & 3 & 13 & 81 & $\mathrm{x}$ \\
\hline Lead & NEC & CR14 & NEC & 679 & 76 & 2 & 21 & 74 & \\
\hline Lead & NEC & HA28 & NEC & 127 & 71 & 2 & 27 & 69 & \\
\hline Zinc & TEC & HA14 & ERL & 159 & 81 & 16 & 3 & 78 & $\mathrm{x}$ \\
\hline Zinc & TEC & HA14 & TEL & 94.15015 & 78 & 22 & 0 & 78 & \\
\hline Zinc & TEC & HA28 & TEL & 98.09154 & 63 & 31 & 6 & 57 & \\
\hline Zinc & TEC & HA28 & ERL & 113 & 63 & 29 & 8 & 55 & \\
\hline Zinc & TEC & CR14 & ERL & 381 & 64 & 26 & 10 & 54 & \\
\hline Zinc & TEC & CR14 & TEL & 280.8327 & 57 & 36 & 7 & 50 & \\
\hline Zinc & PEC & CR14 & PEL & 1532.482 & 83 & 2 & 14 & 81 & $\mathrm{x}$ \\
\hline Zinc & PEC & CR14 & ERM & 2750 & 81 & 2 & 17 & 79 & \\
\hline Zinc & PEC & HA14 & PEL & 384.043 & 75 & 3 & 22 & 72 & \\
\hline Zinc & PEC & HA14 & ERM & 422 & 75 & 3 & 22 & 72 & \\
\hline Zinc & PEC & HA28 & PEL & 543.9917 & 74 & 6 & 19 & 68 & \\
\hline Zinc & PEC & HA28 & ERM & 547 & 74 & 6 & 19 & 68 & \\
\hline Zinc & NEC & HA14 & NEC & 541 & 72 & 3 & 25 & 69 & $\mathrm{x}$ \\
\hline Zinc & NEC & HA28 & NEC & 1300 & 69 & 2 & 29 & 67 & \\
\hline \multicolumn{10}{|c|}{ Organics (ug/kg) } \\
\hline Naphthalene & TEC & CA14 & TEL & 32.75 & 78 & 22 & 0 & 78 & $\mathrm{x}$ \\
\hline Naphthalene & TEC & CR14 & ERL & 55 & 79 & 19 & 2 & 77 & \\
\hline Naphthalene & TEC & CR14 & TEL & 34.39 & 76 & 24 & 0 & 76 & \\
\hline Naphthalene & TEC & CA14 & ERL & 55 & 78 & 19 & 3 & 75 & \\
\hline Naphthalene & TEC & HA28 & TEL & 14.65 & 56 & 37 & 6 & 50 & \\
\hline Naphthalene & TEC & HA28 & ERL & 13 & 55 & 40 & 5 & 50 & \\
\hline Naphthalene & PEC & CA14 & PEL & 687.39 & 81 & 2 & 17 & 79 & $\mathrm{x}$ \\
\hline Naphthalene & PEC & CR14 & ERM & 1890 & 81 & 2 & 17 & 79 & \\
\hline Naphthalene & PEC & CA14 & ERM & 325 & 78 & 0 & 22 & 78 & \\
\hline Naphthalene & PEC & CR14 & PEL & 285.04 & 75 & 3 & 22 & 72 & \\
\hline Naphthalene & PEC & HA28 & PEL & 139.64 & 63 & 13 & 24 & 50 & \\
\hline Naphthalene & PEC & HA28 & ERM & 97.5 & 61 & 15 & 24 & 46 & \\
\hline Naphthalene & NEC & CA14 & NEC & 290 & 75 & 3 & 22 & 72 & $\mathrm{x}$ \\
\hline Naphthalene & NEC & HA28 & NEC & 1400 & 68 & 2 & 31 & 66 & \\
\hline Fluorene & TEC & HA14 & TEL & 34.64 & 75 & 25 & 0 & 75 & $\mathrm{x}$ \\
\hline Fluorene & TEC & HA14 & ERL & 50 & 75 & 22 & 3 & 72 & \\
\hline Fluorene & TEC & CR14 & TEL & 29.66 & 74 & 24 & 2 & 72 & \\
\hline
\end{tabular}


A-6

Table A.1 (continued)

\begin{tabular}{|c|c|c|c|c|c|c|c|c|c|}
\hline Chemical & $\begin{array}{l}\text { BMK } \\
\text { Type }^{b} \\
\end{array}$ & Test $^{c}$ & $\mathrm{SEC}^{d}$ & Conc. & $\begin{array}{c}\text { Total } \\
\text { Correct } \\
(\%)^{e}\end{array}$ & $\begin{array}{c}\text { False } \\
\text { Positives } \\
(\%)^{f} \\
\end{array}$ & $\begin{array}{c}\text { False } \\
\text { Negatives } \\
(\%)^{\mathrm{g}}\end{array}$ & Score $^{h}$ & $\begin{array}{c}\text { Selected } \\
\text { BMK }^{i} \\
\end{array}$ \\
\hline Fluorene & TEC & CR14 & ERL & 88 & 74 & 19 & 7 & 67 & \\
\hline Fluorene & PEC & CR14 & PEL & 651.92 & 83 & 2 & 14 & 81 & $\mathrm{x}$ \\
\hline Fluorene & PEC & HA14 & PEL & 385.68 & 81 & 0 & 19 & 81 & \\
\hline Fluorene & PEC & CR14 & ERM & 1700 & 81 & 2 & 17 & 79 & \\
\hline Fluorene & PEC & HA14 & ERM & 595 & 78 & 0 & 22 & 78 & \\
\hline Fluorene & PEC & HA28 & ERM & 140 & 61 & 13 & 26 & 48 & \\
\hline Fluorene & PEC & HA28 & PEL & 149.67 & 60 & 13 & 27 & 47 & \\
\hline Fluorene & NEC & CR14 & NEC & 1800 & 79 & 2 & 19 & 77 & $\mathrm{x}$ \\
\hline Fluorene & NEC & HA14 & NEC & 290 & 78 & 3 & 19 & 75 & \\
\hline Fluorene & NEC & HA28 & NEC & 3000 & 63 & 2 & 35 & 61 & \\
\hline Phenanthrene & TEC & CR14 & ERL & 350 & 81 & 17 & 2 & 79 & $\mathrm{x}$ \\
\hline Phenanthrene & TEC & HA14 & ERL & 390 & 81 & 16 & 3 & 78 & \\
\hline Phenanthrene & TEC & HA14 & TEL & 197.48 & 75 & 25 & 0 & 75 & \\
\hline Phenanthrene & TEC & CR14 & TEL & 95.39 & 71 & 26 & 2 & 69 & \\
\hline Phenanthrene & TEC & HA28 & TEL & 18.73 & 68 & 27 & 5 & 63 & \\
\hline Phenanthrene & TEC & HA28 & ERL & 27 & 65 & 27 & 8 & 57 & \\
\hline Phenanthrene & PEC & CR14 & PEL & 1142.37 & 83 & 2 & 14 & 81 & $\mathrm{x}$ \\
\hline Phenanthrene & PEC & HA14 & ERM & 1100 & 81 & 0 & 19 & 81 & \\
\hline Phenanthrene & PEC & CR14 & ERM & 2250 & 81 & 2 & 17 & 79 & \\
\hline Phenanthrene & PEC & HA14 & PEL & 777.82 & 78 & 3 & 19 & 75 & \\
\hline Phenanthrene & PEC & HA28 & ERM & 345 & 66 & 13 & 21 & 53 & \\
\hline Phenanthrene & PEC & HA28 & PEL & 409.05 & 63 & 13 & 24 & 50 & \\
\hline Phenanthrene & NEC & CR14 & NEC & 6100 & 79 & 2 & 19 & 77 & $\mathrm{x}$ \\
\hline Phenanthrene & NEC & HA14 & NEC & 1000 & 78 & 3 & 19 & 75 & \\
\hline Phenanthrene & NEC & HA28 & NEC & 20000 & 61 & 2 & 37 & 59 & \\
\hline Anthracene & TEC & HA14 & TEL & 31.62 & 78 & 22 & 0 & 78 & $\mathrm{x}$ \\
\hline Anthracene & TEC & HA14 & ERL & 100 & 78 & 19 & 3 & 75 & \\
\hline Anthracene & TEC & CR14 & TEL & 37.42 & 74 & 24 & 2 & 72 & \\
\hline Anthracene & TEC & CR14 & ERL & 140 & 74 & 19 & 7 & 67 & \\
\hline Anthracene & PEC & CR14 & PEL & 547.72 & 83 & 2 & 14 & 81 & $\mathrm{x}$ \\
\hline Anthracene & PEC & CR14 & ERM & 1250 & 81 & 2 & 17 & 79 & \\
\hline Anthracene & PEC & HA14 & PEL & 409.27 & 78 & 0 & 22 & 78 & \\
\hline Anthracene & PEC & HA14 & ERM & 670 & 78 & 0 & 22 & 78 & \\
\hline Anthracene & PEC & HA28 & PEL & 167.33 & 63 & 11 & 26 & 52 & \\
\hline Anthracene & PEC & HA28 & ERM & 140 & 61 & 15 & 24 & 46 & \\
\hline Anthracene & NEC & CR14 & NEC & 1700 & 79 & 2 & 19 & 77 & $\mathrm{x}$ \\
\hline Anthracene & NEC & HA14 & NEC & 290 & 75 & 3 & 22 & 72 & \\
\hline Anthracene & NEC & HA28 & NEC & 2000 & 65 & 2 & 34 & 63 & \\
\hline Fluoranthene & TEC & CR14 & TEL & 64.23 & 69 & 31 & 0 & 69 & $\mathrm{x}$ \\
\hline Fluoranthene & TEC & HA14 & TEL & 144.22 & 69 & 28 & 3 & 66 & \\
\hline Fluoranthene & TEC & HA14 & ERL & 160 & 69 & 28 & 3 & 66 & \\
\hline Fluoranthene & TEC & CR14 & ERL & 110 & 67 & 31 & 2 & 65 & \\
\hline Fluoranthene & TEC & HA28 & TEL & 31.46 & 56 & 32 & 11 & 45 & \\
\hline Fluoranthene & TEC & HA28 & ERL & 33 & 56 & 32 & 11 & 45 & \\
\hline Fluoranthene & PEC & HA14 & PEL & 834.27 & 84 & 3 & 13 & 81 & $\mathrm{x}$ \\
\hline Fluoranthene & PEC & CR14 & PEL & 1484.59 & 83 & 2 & 14 & 81 & \\
\hline
\end{tabular}


A-7

Table A.1 (continued)

\begin{tabular}{|c|c|c|c|c|c|c|c|c|c|}
\hline Chemical & $\begin{array}{l}\text { BMK } \\
\text { Type }^{b}\end{array}$ & Test $^{c}$ & $\mathrm{SEC}^{d}$ & Conc. & $\begin{array}{c}\text { Total } \\
\text { Correct } \\
(\%)^{e} \\
\end{array}$ & $\begin{array}{c}\text { False } \\
\text { Positives } \\
(\%)^{f} \\
\end{array}$ & $\begin{array}{c}\text { False } \\
\text { Negatives } \\
(\%)^{\mathrm{g}}\end{array}$ & Score $^{h}$ & $\begin{array}{c}\text { Selected } \\
\text { BMK }^{i} \\
\end{array}$ \\
\hline Fluoranthene & PEC & CR14 & ERM & 2900 & 81 & 2 & 17 & 79 & \\
\hline Fluoranthene & PEC & HA14 & ERM & 1200 & 78 & 3 & 19 & 75 & \\
\hline Fluoranthene & PEC & HA28 & PEL & 318.59 & 56 & 19 & 24 & 37 & \\
\hline Fluoranthene & PEC & HA28 & ERM & 175 & 55 & 23 & 23 & 32 & \\
\hline Fluoranthene & NEC & CR14 & NEC & 7500 & 79 & 2 & 19 & 77 & $\mathrm{x}$ \\
\hline Fluoranthene & NEC & HA14 & NEC & 1200 & 78 & 3 & 19 & 75 & \\
\hline Fluoranthene & NEC & HA28 & NEC & 10000 & 63 & 2 & 35 & 61 & \\
\hline Pyrene & TEC & HA14 & ERL & 570 & 81 & 16 & 3 & 78 & $\mathrm{x}$ \\
\hline Pyrene & TEC & HA14 & TEL & 231.47 & 72 & 25 & 3 & 69 & \\
\hline Pyrene & TEC & CR14 & ERL & 120 & 69 & 29 & 2 & 67 & \\
\hline Pyrene & TEC & CR14 & TEL & 67.53 & 67 & 31 & 2 & 65 & \\
\hline Pyrene & TEC & HA28 & ERL & 40 & 60 & 32 & 8 & 52 & \\
\hline Pyrene & TEC & HA28 & TEL & 44.27 & 55 & 32 & 13 & 42 & \\
\hline Pyrene & PEC & CR14 & ERM & 3225 & 81 & 2 & 17 & 79 & $\mathrm{x}$ \\
\hline Pyrene & PEC & CR14 & PEL & 1684.64 & 81 & 5 & 14 & 76 & \\
\hline Pyrene & PEC & HA14 & ERM & 1100 & 78 & 3 & 19 & 75 & \\
\hline Pyrene & PEC & HA14 & PEL & 908.3 & 78 & 6 & 16 & 72 & \\
\hline Pyrene & PEC & HA28 & PEL & 493.2 & 63 & 16 & 21 & 47 & \\
\hline Pyrene & PEC & HA28 & ERM & 347.5 & 61 & 18 & 21 & 43 & \\
\hline Pyrene & NEC & CR14 & NEC & 6100 & 79 & 2 & 19 & 77 & $\mathrm{x}$ \\
\hline Pyrene & NEC & HA14 & NEC & 1800 & 75 & 3 & 22 & 72 & \\
\hline Pyrene & NEC & HA28 & NEC & 9000 & 65 & 2 & 34 & 63 & \\
\hline Benz(a)anthracene & TEC & HA14 & ERL & 260 & 88 & 9 & 3 & 85 & $\mathrm{x}$ \\
\hline Benz(a)anthracene & TEC & CR14 & ERL & 300 & 81 & 12 & 7 & 74 & \\
\hline Benz(a)anthracene & TEC & HA14 & TEL & 103.25 & 72 & 25 & 3 & 69 & \\
\hline Benz(a)anthracene & TEC & CR14 & TEL & 75.5 & 67 & 29 & 5 & 62 & \\
\hline Benz(a)anthracene & TEC & HA28 & TEL & 15.72 & 56 & 34 & 10 & 46 & \\
\hline Benz(a)anthracene & TEC & HA28 & ERL & 19 & 55 & 34 & 11 & 44 & \\
\hline Benz(a)anthracene & PEC & CR14 & ERM & 4200 & 83 & 0 & 17 & 83 & $\mathrm{x}$ \\
\hline Benz(a)anthracene & PEC & CR14 & PEL & 1194.99 & 81 & 2 & 17 & 79 & \\
\hline Benz(a)anthracene & PEC & HA14 & ERM & 490 & 78 & 3 & 19 & 75 & \\
\hline Benz(a)anthracene & PEC & HA14 & PEL & 363.73 & 78 & 6 & 16 & 72 & \\
\hline Benz(a)anthracene & PEC & HA28 & PEL & 284.6 & 68 & 10 & 23 & 58 & \\
\hline Benz(a)anthracene & PEC & HA28 & ERM & 300 & 68 & 10 & 23 & 58 & \\
\hline Benz(a)anthracene & NEC & CR14 & NEC & 3500 & 81 & 2 & 17 & 79 & $\mathrm{x}$ \\
\hline Benz(a)anthracene & NEC & HA14 & NEC & 690 & 72 & 3 & 25 & 69 & \\
\hline Benz(a)anthracene & NEC & HA28 & NEC & 3000 & 68 & 2 & 31 & 66 & \\
\hline Chrysene & TEC & CR14 & ERL & 500 & 88 & 5 & 7 & 81 & $\mathrm{x}$ \\
\hline Chrysene & TEC & HA14 & ERL & 330 & 84 & 13 & 3 & 81 & \\
\hline Chrysene & TEC & CR14 & TEL & 122.47 & 71 & 24 & 5 & 66 & \\
\hline Chrysene & TEC & HA14 & TEL & 135.94 & 69 & 28 & 3 & 66 & \\
\hline Chrysene & TEC & HA28 & TEL & 26.83 & 52 & 35 & 13 & 39 & \\
\hline Chrysene & TEC & HA28 & ERL & 30 & 52 & 34 & 15 & 37 & \\
\hline Chrysene & PEC & CR14 & ERM & 5200 & 83 & 0 & 17 & 83 & $\mathrm{x}$ \\
\hline Chrysene & PEC & HA14 & ERM & 690 & 81 & 0 & 19 & 81 & \\
\hline Chrysene & PEC & CR14 & PEL & 1512.61 & 81 & 2 & 17 & 79 & \\
\hline
\end{tabular}


A-8

Table A.1 (continued)

\begin{tabular}{|c|c|c|c|c|c|c|c|c|c|}
\hline Chemical & $\begin{array}{l}\text { BMK } \\
\text { Type }^{b} \\
\end{array}$ & Test $^{c}$ & $\mathrm{SEC}^{d}$ & Conc. & $\begin{array}{c}\text { Total } \\
\text { Correct } \\
(\%)^{e}\end{array}$ & $\begin{array}{c}\text { False } \\
\text { Positives } \\
(\%)^{f} \\
\end{array}$ & $\begin{array}{c}\text { False } \\
\text { Negatives } \\
(\%)^{\mathrm{g}} \\
\end{array}$ & Score $^{h}$ & $\begin{array}{c}\text { Selected } \\
\text { BMK }^{i} \\
\end{array}$ \\
\hline Chrysene & PEC & HA14 & PEL & 551 & 81 & 3 & 16 & 78 & \\
\hline Chrysene & PEC & HA28 & ERM & 500 & 73 & 3 & 24 & 70 & \\
\hline Chrysene & PEC & HA28 & PEL & 406.2 & 68 & 10 & 23 & 58 & \\
\hline Chrysene & NEC & CR14 & NEC & 4000 & 81 & 2 & 17 & 79 & $\mathrm{x}$ \\
\hline Chrysene & NEC & HA14 & NEC & 600 & 81 & 3 & 16 & 78 & \\
\hline Chrysene & NEC & HA28 & NEC & 3000 & 68 & 2 & 31 & 66 & \\
\hline Benzo(a)pyrene & TEC & HA14 & ERL & 350 & 88 & 3 & 9 & 79 & $\mathrm{x}$ \\
\hline Benzo(a)pyrene & TEC & HA14 & TEL & 119.79 & 75 & 22 & 3 & 72 & \\
\hline Benzo(a)pyrene & TEC & CR14 & ERL & 210 & 74 & 21 & 5 & 69 & \\
\hline Benzo(a)pyrene & TEC & CR14 & TEL & 51.23 & 69 & 26 & 5 & 64 & \\
\hline Benzo(a)pyrene & TEC & HA28 & ERL & 84 & 60 & 21 & 19 & 41 & \\
\hline Benzo(a)pyrene & TEC & HA28 & TEL & 32.4 & 53 & 29 & 18 & 35 & \\
\hline Benzo(a)pyrene & PEC & HA14 & PEL & 393.7 & 84 & 3 & 13 & 81 & $\mathrm{x}$ \\
\hline Benzo(a)pyrene & PEC & CR14 & ERM & 8500 & 81 & 0 & 19 & 81 & \\
\hline Benzo(a)pyrene & PEC & CR14 & PEL & 1724.82 & 81 & 2 & 17 & 79 & \\
\hline Benzo(a)pyrene & PEC & HA14 & ERM & 620 & 78 & 0 & 22 & 78 & \\
\hline Benzo(a)pyrene & PEC & HA28 & ERM & 465 & 71 & 2 & 27 & 69 & \\
\hline Benzo(a)pyrene & PEC & HA28 & PEL & 319.84 & 71 & 5 & 24 & 66 & \\
\hline Benzo(a)pyrene & NEC & HA14 & NEC & 440 & 84 & 3 & 13 & 81 & $\mathrm{x}$ \\
\hline Benzo(a)pyrene & NEC & CR14 & NEC & 5800 & 81 & 2 & 17 & 79 & \\
\hline Benzo(a)pyrene & NEC & HA28 & NEC & 1000 & 68 & 2 & 31 & 66 & \\
\hline Indeno $(1,2,3-c, d)$ pyrene & TEC & HA14 & ERL & 78 & 69 & 28 & 3 & 66 & $\mathrm{x}$ \\
\hline Indeno $(1,2,3-c, d)$ pyrene & TEC & CR14 & TEL & 17.32 & 67 & 31 & 2 & 65 & \\
\hline Indeno $(1,2,3-c, d)$ pyrene & TEC & CR14 & ERL & 30 & 67 & 31 & 2 & 65 & \\
\hline Indeno $(1,2,3-c, d)$ pyrene & TEC & HA14 & TEL & 86.53 & 66 & 28 & 6 & 60 & \\
\hline Indeno $(1,2,3-c, d)$ pyrene & TEC & HA28 & ERL & 30 & 56 & 32 & 12 & 44 & \\
\hline Indeno $(1,2,3-c, d)$ pyrene & TEC & HA28 & TEL & 17.32 & 54 & 33 & 12 & 42 & \\
\hline Indeno $(1,2,3-c, d)$ pyrene & PEC & CR14 & PEL & 836.66 & 81 & 2 & 17 & 79 & $\mathrm{x}$ \\
\hline Indeno $(1,2,3-c, d)$ pyrene & PEC & CR14 & ERM & 2800 & 81 & 2 & 17 & 79 & \\
\hline Indeno $(1,2,3-c, d)$ pyrene & PEC & HA14 & PEL & 326.5 & 78 & 0 & 22 & 78 & \\
\hline Indeno $(1,2,3-c, d)$ pyrene & PEC & HA14 & ERM & 410 & 78 & 0 & 22 & 78 & \\
\hline Indeno $(1,2,3-c, d)$ pyrene & PEC & HA28 & PEL & 239.79 & 67 & 11 & 23 & 56 & \\
\hline Indeno $(1,2,3-c, d)$ pyrene & PEC & HA28 & ERM & 250 & 67 & 11 & 23 & 56 & \\
\hline Indeno $(1,2,3-c, d)$ pyrene & NEC & CR14 & NEC & 3800 & 81 & 2 & 17 & 79 & $\mathrm{x}$ \\
\hline Indeno $(1,2,3-c, d)$ pyrene & NEC & HA14 & NEC & 290 & 75 & 6 & 19 & 69 & \\
\hline Indeno $(1,2,3-c, d)$ pyrene & NEC & HA28 & NEC & 770 & 70 & 2 & 28 & 68 & \\
\hline Benzo(g,h,i)perylene & TEC & CR14 & ERL & 290 & 83 & 7 & 10 & 73 & $\mathrm{x}$ \\
\hline Benzo(g,h,i)perylene & TEC & CR14 & TEL & 74.23 & 71 & 24 & 5 & 66 & \\
\hline Benzo(g,h,i)perylene & TEC & HA14 & TEL & 89.49 & 69 & 28 & 3 & 66 & \\
\hline Benzo(g,h,i)perylene & TEC & HA14 & ERL & 91 & 69 & 28 & 3 & 66 & \\
\hline Benzo(g,h,i)perylene & TEC & HA28 & ERL & 13 & 52 & 37 & 11 & 41 & \\
\hline Benzo(g,h,i)perylene & TEC & HA28 & TEL & 15.51 & 52 & 35 & 13 & 39 & \\
\hline Benzo(g,h,i)perylene & PEC & CR14 & ERM & 6300 & 83 & 0 & 17 & 83 & $\mathrm{x}$ \\
\hline Benzo(g,h,i)perylene & PEC & CR14 & PEL & 1279.84 & 81 & 2 & 17 & 79 & \\
\hline Benzo(g,h,i)perylene & PEC & HA14 & PEL & 349.14 & 78 & 0 & 22 & 78 & \\
\hline $\operatorname{Benzo}(\mathrm{g}, \mathrm{h}, \mathrm{i})$ perylene & PEC & HA14 & ERM & 460 & 78 & 0 & 22 & 78 & \\
\hline
\end{tabular}


A-9

Table A.1 (continued)

\begin{tabular}{|c|c|c|c|c|c|c|c|c|c|}
\hline Chemical & $\begin{array}{l}\text { BMK } \\
\text { Type }^{b}\end{array}$ & Test $^{c}$ & $\mathrm{SEC}^{d}$ & Conc. & $\begin{array}{c}\text { Total } \\
\text { Correct } \\
(\%)^{e}\end{array}$ & $\begin{array}{c}\text { False } \\
\text { Positives } \\
(\%)^{f} \\
\end{array}$ & $\begin{array}{c}\text { False } \\
\text { Negatives } \\
(\%)^{\mathrm{g}}\end{array}$ & Score $^{h}$ & $\begin{array}{c}\text { Selected } \\
\text { BMK }^{i} \\
\end{array}$ \\
\hline Benzo(g,h,i)perylene & PEC & HA28 & ERM & 275 & 73 & 3 & 24 & 70 & \\
\hline Benzo(g,h,i)perylene & PEC & HA28 & PEL & 251.5 & 71 & 6 & 23 & 65 & \\
\hline Benzo(g,h,i)perylene & NEC & CR14 & NEC & 3800 & 81 & 2 & 17 & 79 & $\mathrm{x}$ \\
\hline Benzo(g,h,i)perylene & NEC & HA14 & NEC & 310 & 75 & 3 & 22 & 72 & \\
\hline Benzo(g,h,i)perylene & NEC & HA28 & NEC & 1200 & 68 & 2 & 31 & 66 & \\
\hline Benzo(b,k)fluoranthene & TEC & HA28 & TEL & 27.2 & 53 & 30 & 16 & 37 & $\mathrm{x}$ \\
\hline Benzo(b,k)fluoranthene & TEC & HA28 & ERL & 37 & 53 & 30 & 16 & 37 & \\
\hline Benzo(b,k)fluoranthene & PEC & HA28 & PEL & 157.64 & 56 & 19 & 26 & 37 & \\
\hline Benzo(b,k)fluoranthene & NEC & HA28 & NEC & 4000 & 67 & 2 & 30 & 65 & $\mathrm{x}$ \\
\hline Dibenz(a,h)anthracene & PEC & HA28 & PEL & 28.2 & 56 & 16 & 28 & 40 & $\mathrm{x}$ \\
\hline Dibenz(a,h)anthracene & PEC & HA28 & ERM & 15 & 56 & 21 & 23 & 35 & \\
\hline Dibenz(a,h)anthracene & NEC & HA28 & NEC & 870 & 67 & 2 & 30 & 65 & $\mathrm{x}$ \\
\hline PAH Total (others) & TEC & HA14 & ERL & 3553 & 78 & 19 & 3 & 75 & $\mathrm{x}$ \\
\hline PAH Total (others) & TEC & CR14 & ERL & 1297 & 74 & 24 & 2 & 72 & \\
\hline PAH Total (others) & TEC & HA14 & TEL & 1589.4 & 69 & 28 & 3 & 66 & \\
\hline PAH Total (others) & TEC & CR14 & TEL & 588.47 & 67 & 31 & 2 & 65 & \\
\hline PAH Total (others) & TEC & HA28 & ERL & 240 & 56 & 35 & 8 & 48 & \\
\hline PAH Total (others) & TEC & HA28 & TEL & 264.05 & 55 & 34 & 11 & 44 & \\
\hline PAH Total (others) & PEC & CR14 & PEL & 13660.65 & 81 & 2 & 17 & 79 & $\mathrm{x}$ \\
\hline PAH Total (others) & PEC & CR14 & ERM & 33819 & 81 & 2 & 17 & 79 & \\
\hline PAH Total (others) & PEC & HA14 & PEL & 6736.42 & 81 & 3 & 16 & 78 & \\
\hline PAH Total (others) & PEC & HA14 & ERM & 8498 & 78 & 3 & 19 & 75 & \\
\hline PAH Total (others) & PEC & HA28 & PEL & 3368.09 & 61 & 16 & 23 & 45 & \\
\hline PAH Total (others) & PEC & HA28 & ERM & 2226.5 & 58 & 21 & 21 & 37 & \\
\hline PAH Total (others) & NEC & CR14 & NEC & 84600 & 79 & 2 & 19 & 77 & $\mathrm{x}$ \\
\hline PAH Total (others) & NEC & HA14 & NEC & 9240 & 75 & 3 & 22 & 72 & \\
\hline PAH Total (others) & NEC & HA28 & NEC & 62220 & 66 & 2 & 32 & 64 & \\
\hline PAH Low & TEC & HA14 & ERL & 786 & 78 & 19 & 3 & 75 & $\mathrm{x}$ \\
\hline PAH Low & TEC & HA14 & TEL & 387.46 & 75 & 25 & 0 & 75 & \\
\hline PAH Low & TEC & CR14 & ERL & 653 & 76 & 21 & 2 & 74 & \\
\hline PAH Low & TEC & CR14 & TEL & 231.4 & 74 & 24 & 2 & 72 & \\
\hline PAH Low & TEC & HA28 & TEL & 76.42 & 63 & 29 & 8 & 55 & \\
\hline PAH Low & TEC & HA28 & ERL & 80 & 63 & 29 & 8 & 55 & \\
\hline PAH Low & PEC & HA14 & ERM & 3369 & 81 & 0 & 19 & 81 & $\mathrm{x}$ \\
\hline PAH Low & PEC & CR14 & PEL & 4140.86 & 81 & 2 & 17 & 79 & \\
\hline PAH Low & PEC & CR14 & ERM & 7204.5 & 81 & 2 & 17 & 79 & \\
\hline PAH Low & PEC & HA14 & PEL & 2919.52 & 78 & 3 & 19 & 75 & \\
\hline PAH Low & PEC & HA28 & PEL & 1176.59 & 61 & 13 & 26 & 48 & \\
\hline PAH Low & PEC & HA28 & ERM & 653 & 63 & 16 & 21 & 47 & \\
\hline PAH Low & NEC & HA14 & NEC & 3040 & 78 & 3 & 19 & 75 & $\mathrm{x}$ \\
\hline PAH Low & NEC & CR14 & NEC & 33600 & 76 & 2 & 21 & 74 & \\
\hline PAH Low & NEC & HA28 & NEC & 29380 & 65 & 2 & 34 & 63 & \\
\hline PAH High & TEC & HA14 & ERL & 2900 & 84 & 13 & 3 & 81 & $\mathrm{x}$ \\
\hline PAH High & TEC & HA14 & TEL & 1228.01 & 69 & 28 & 3 & 66 & \\
\hline PAH High & TEC & CR14 & TEL & 309.81 & 67 & 31 & 2 & 65 & \\
\hline PAH High & TEC & CR14 & ERL & 486 & 67 & 31 & 2 & 65 & \\
\hline
\end{tabular}


A-10

Table A.1 (continued)

\begin{tabular}{|c|c|c|c|c|c|c|c|c|c|}
\hline Chemical & $\begin{array}{l}\text { BMK } \\
\text { Type }^{b} \\
\end{array}$ & Test $^{c}$ & $\mathrm{SEC}^{d}$ & Conc. & $\begin{array}{c}\text { Total } \\
\text { Correct } \\
(\%)^{e}\end{array}$ & $\begin{array}{c}\text { False } \\
\text { Positives } \\
(\%)^{f} \\
\end{array}$ & $\begin{array}{c}\text { False } \\
\text { Negatives } \\
(\%)^{\mathrm{g}} \\
\end{array}$ & Score $^{h}$ & $\begin{array}{c}\text { Selected } \\
\text { BMK }^{i} \\
\end{array}$ \\
\hline PAH High & TEC & HA28 & ERL & 170 & 55 & 37 & 8 & 47 & \\
\hline PAH High & TEC & HA28 & TEL & 192.95 & 52 & 35 & 13 & 39 & \\
\hline PAH High & PEC & HA14 & PEL & 4353.82 & 84 & 3 & 13 & 81 & $\mathrm{x}$ \\
\hline PAH High & PEC & CR14 & PEL & 10122.54 & 81 & 2 & 17 & 79 & \\
\hline PAH High & PEC & CR14 & ERM & 26614.5 & 81 & 2 & 17 & 79 & \\
\hline PAH High & PEC & HA14 & ERM & 5650 & 78 & 3 & 19 & 75 & \\
\hline PAH High & PEC & HA28 & PEL & 2338.4 & 60 & 19 & 21 & 41 & \\
\hline PAH High & PEC & HA28 & ERM & 1747 & 58 & 21 & 21 & 37 & \\
\hline PAH High & NEC & CR14 & NEC & 51000 & 79 & 2 & 19 & 77 & $\mathrm{x}$ \\
\hline PAH High & NEC & HA14 & NEC & 6200 & 75 & 3 & 22 & 72 & \\
\hline PAH High & NEC & HA28 & NEC & 32840 & 68 & 2 & 31 & 66 & \\
\hline PCB Total & TEC & HA28 & TEL & 31.62 & 69 & 14 & 17 & 52 & $\mathrm{x}$ \\
\hline PCB Total & TEC & HA28 & ERL & 50 & 69 & 14 & 17 & 52 & \\
\hline PCB Total & PEC & HA28 & PEL & 244.66 & 76 & 0 & 24 & 76 & $\mathrm{x}$ \\
\hline PCB Total & PEC & HA28 & ERM & 730 & 76 & 0 & 24 & 76 & \\
\hline PCB Total & NEC & HA28 & NEC & 194 & 72 & 3 & 24 & 69 & $\mathrm{x}$ \\
\hline
\end{tabular}

Source: U.S. Environmental Protection Agency 1996. Calculation and Evaluation of Sediment Effect Concentrations for the Amphipod Hyalella azteca and the Midge Chironomus riparius, EPA 905-R96-008, Great Lakes National Program Office, Chicago, Ill.

${ }^{a}$ All SECs must have \% Total Correct values $>50 \%$, TECs must have \% False Negative values < 25\%, and PECs and NEC must have $\%$ False Positive values $<25 \%$.

${ }^{b}$ BMK Type = Benchmark Type; TEC $=$ Threshold Effect Concentration (i.e., ERLs and TELs); PEC = Probable Effect Concentration (i.e., ERMs and PELs); and NEC = high No Effect Concentration.

${ }^{c} \mathrm{CR} 14=$ Chironomus riparius 14-day test, HA14 $=$ Hyalella azteca 14-day test, and HA28 = Hyalella azteca 28-day test.

${ }^{d}$ ERL = Effects Range Low, ERM = Effects Range Median, TEL = Threshold Effects Level, and PEL = Probable Effects Level.

${ }^{e} \%$ Total Correct $=$ the percentage of samples correctly identified as toxic or non-toxic

${ }^{f} \%$ False Positives $=$ the percentage of samples incorrectly identified as toxic.

${ }^{g} \%$ False Negatives $=$ the percentage of samples incorrectly identified as non-toxic.

"The score for TEC benchmarks $=\%$ Total Correct (-) \% False Negatives. The score for PEC and NEC benchmarks $=\%$ Total Correct (-) \% False Positives.

i" $\mathrm{x}$ " indicates the SEC selected as the representative benchmark for that chemical and benchmark type. Selection criteria, in order of priority, are 1) highest score, 2) highest \% Total Correct, and 3) lowest concentration. 